\title{
Recommendations for Human Epidermal Growth Factor Receptor 2 Testing in Breast Cancer
}

\author{
American Society of Clinical Oncology/College of American Pathologists \\ Clinical Practice Guideline Update
}

\begin{abstract}
Antonio C. Wolff*, M. Elizabeth H. Hammond*, David G. Hicks*, Mitch Dowsett*, Lisa M. McShane*, Kimberly H. Allison, Donald C. Allred, John M.S. Bartlett, Michael Bilous, Patrick Fitzgibbons, Wedad Hanna, Robert B. Jenkins, Pamela B. Mangu, Soonmyung Paik, Edith A. Perez, Michael F. Press, Patricia A. Spears, Gail H. Vance, Giuseppe Viale, and Daniel F. Hayes*
\end{abstract}

Purpose. To update the American Society of Clinical Oncology (ASCO)/College of American Pathologists (CAP) guideline recommendations for human epidermal growth factor receptor 2 (HER2) testing in breast cancer to improve the accuracy of HER2 testing and its utility as a predictive marker in invasive breast cancer.

Methods. ASCO/CAP convened an Update Committee that included coauthors of the $\mathbf{2 0 0 7}$ guideline to conduct a systematic literature review and update recommendations for optimal HER2 testing.

Results. The Update Committee identified criteria and areas requiring clarification to improve the accuracy of HER2 testing by immunohistochemistry (IHC) or in situ

American Society of Clinical Oncology Clinical Practice Guideline Committee approval: April 26, 2013; College of American Pathologists approval: June 21, 2013.

Published as an Early Online Release October 7, 2013

*Steering Committee member.

This guideline was developed through a collaboration between the American Society of Clinical Oncology and the College of American Pathologists and has been published jointly by invitation and consent in both the Journal of Clinical Oncology and the Archives of Pathology \& Laboratory Medicine. It has been edited in accordance with the standards established at the Journal of Clinical Oncology. Copyright (c) 2013 American Society of Clinical Oncology and College of American Pathologists. All rights reserved. No part of this document may be reproduced or transmitted in any form or by any means, electronic or mechanical, including photocopy, recording, or any information storage and retrieval system, without written permission by the American Society of Clinical Oncology or College of American Pathologists.

Editor's Note: This article summarizes the Recommendations for Human Epidermal Growth Factor Receptor 2 Testing in Breast Cancer: American Society of Clinical Oncology/College of American Pathologists Clinical Practice Guideline Update and provides the updated recommendations with brief discussions of the relevant literature for each. Additional information, including extensive Data Supplements, used by the Update Committee to formulate these recommendations is available at www.asco.org/guidelines/her2.

Author affiliations appear at the end of this article.

Authors' disclosures of potential conflicts of interest and author contributions are found at the end of this article.

Corresponding author: American Society of Clinical Oncology, 2318 Mill Rd, Suite 800, Alexandria, VA 22314; e-mail: guidelines@ asco.org.

Arch Pathol Lab Med_Vol 138, February 2014 hybridization (ISH). The guideline was reviewed and approved by both organizations.

Recommendations. The Update Committee recommends that HER2 status (HER2 negative or positive) be determined in all patients with invasive (early stage or recurrence) breast cancer on the basis of one or more HER2 test results (negative, equivocal, or positive). Testing criteria define HER2-positive status when (on observing within an area of tumor that amounts to $>10 \%$ of contiguous and homogeneous tumor cells) there is evidence of protein overexpression (IHC) or gene amplification (HER2 copy number or HER 2/CEP17 ratio by ISH based on counting at least 20 cells within the area). If results are equivocal (revised criteria), reflex testing should be performed using an alternative assay (IHC or ISH). Repeat testing should be considered if results seem discordant with other histopathologic findings. Laboratories should demonstrate high concordance with a validated HER2 test on a sufficiently large and representative set of specimens. Testing must be performed in a laboratory accredited by CAP or another accrediting entity. The Update Committee urges providers and health systems to cooperate to ensure the highest quality testing.

(Arch Pathol Lab Med. 2014;138:241-256; doi: 10.5858/ arpa.2013-0953-SA)

n 2007, a joint Expert Panel convened by the American Society of Clinical Oncology (ASCO) and the College of American Pathologists (CAP) met to develop guidelines for when and how to test for the human epidermal growth factor receptor 2 (HER2) gene (also referred to as ERBB2), ${ }^{1,2}$ which is amplified and/or overexpressed in approximately $15 \%$ to $20 \%$ of primary breast cancers. Since then, minor clarifications and updates to the ASCO/CAP HER2 testing guideline have been issued. ${ }^{3-5}$ A detailed rationale for this full 2013 update, as well as additional background information, is available in Data Supplement 1.

In 2012, ASCO and CAP convened an Update Committee to conduct a formal and comprehensive review of the peerreviewed literature published since 2006 and to revise the guideline recommendations as appropriate. Since publication of the 2007 guideline, new diagnostic strategies, like measures of HER2 amplification by bright-field in situ hybridization, DNA expression by microarray, or mRNA 


\section{The Bottom Line}

\section{ASCO Guideline Update}

\section{Recommendations for HER2 Testing in Breast Cancer: ASCO/CAP Guideline Update}

\section{Intervention}

- Recommendations for HER2 testing in breast cancer

\section{Target Audience}

- Medical oncologists, pathologists, and surgeons

\section{Key Recommendations for Oncologists}

- Must request HER2 testing on every primary invasive breast cancer (and on metastatic site, if stage IV and if specimen available) from a patient with breast cancer to guide decision to pursue HER2-targeted therapy. This should be especially considered for a patient who previously tested HER2 negative in a primary tumor and presents with disease recurrence with clinical behavior suggestive of HER2-positive or triple-negative disease.

- Should recommend HER2-targeted therapy if HER2 test result is positive, if there is no apparent histopathologic discordance with HER2 testing (Tables 1 and 2), and if clinically appropriate. If the pathologist or oncologist observes an apparent histopathologic discordance after HER2 testing, the need for additional HER2 testing should be discussed.

- Must delay decision to recommend HER2-targeted therapy if initial HER2 test result is equivocal. Reflex testing should be performed on the same specimen using the alternative test if initial HER2 test result is equivocal or on an alternative specimen (Tables 1 and 2).

- Must not recommend HER2-targeted therapy if HER2 test result is negative and if there is no apparent histopathologic discordance with HER2 testing (Tables 1 and 2). If the pathologist or oncologist observes an apparent histopathologic discordance after HER2 testing, the need for additional HER2 testing should be discussed.

- Should delay decision to recommend HER2-targeted therapy if HER2 status cannot be confirmed as positive or negative after separate HER2 tests (HER2 test result or results equivocal). The oncologist should confer with the pathologist regarding the need for additional HER2 testing on the same or another tumor specimen.

- If the HER2 test result is ultimately deemed to be equivocal, even after reflex testing with an alternative assay (ie, if neither test is unequivocally positive), the oncologist may consider HER2-targeted therapy. The oncologist should also consider the feasibility of testing another tumor specimen to attempt to definitely establish the tumor HER2 status and guide therapeutic decisions. A clinical decision to ultimately consider HER2-targeted therapy in such cases should be individualized on the basis of patient status (comorbidities, prognosis, and so on) and patient preferences after discussing available clinical evidence.

\section{Key Recommendations for Pathologists}

- Must ensure that at least one tumor sample from all patients with breast cancer (early-stage or metastatic disease) is tested for either HER2 protein expression (IHC assay) or HER2 gene expression (ISH assay) using a validated HER2 test.

- In the United States, the ASCO/CAP Guideline Update Committee preferentially recommends the use of an assay that has received FDA approval, although a CLIA-certified laboratory may choose instead to use a laboratory-developed test (LDT). In this case, the analytic performance of the LDT must be prospectively validated in the same clinical laboratory that will perform it, and the test must have documented analytic validity (CAP guidance document). Bright-field ISH assays must be initially validated by comparing them with an FDA-approved FISH assay.

- Must report a HER2 test result as positive if: (a) IHC 3+ positive or (b) ISH positive using either a single-probe ISH or dual-probe ISH (Table 1; Figs 1 to 3). This assumes that there is no apparent histopathologic discordance observed by the pathologist (Table 2).

- Must report a HER2 test result as equivocal and order reflex test on the same specimen (unless the pathologist has concerns about the specimen) using the alternative test if: (a) IHC 2+ equivocal or (b) ISH equivocal using single-probe ISH or dual-probe ISH (Table 1; Figs 1 to 3). This assumes that there is no apparent histopathologic discordance observed by the pathologist (Table 2). Note that there are some rare breast cancers (eg, gland-forming tumors, micropapillary carcinomas) that show IHC 1+ staining that is intense but incomplete (basolateral or $U$ shaped) and that are found to be HER2 amplified. The pathologist should consider also reporting these specimens equivocal and request reflex testing using the alternative test.

- Must report a HER2 test result as negative if a single test (or all tests) performed on a tumor specimen show: (a) IHC 1+ negative or IHC 0 negative or (b) ISH negative using single-probe ISH or dual-probe ISH (Table 1; Figs 1 to 3 ). This assumes that there is no apparent histopathologic discordance observed by the pathologist (Table 2).

- Must report a HER2 test result as indeterminate if technical issues prevent one or both tests (IHC and ISH) performed on a tumor specimen from being reported as positive, negative, or equivocal. This may occur if specimen handling was inadequate, if artifacts (crush or edge artifacts) make interpretation difficult, or if the analytic testing failed. Another specimen should be requested for testing, if possible, and a comment should be included in the pathology report documenting intended action.

- Must ensure that interpretation and reporting guidelines for HER2 testing are followed (Table 1; Data Supplements 7, 8, 9, and 10).

- Should interpret bright-field ISH on the basis of a comparison between patterns in normal breast and tumor cells, because artifactual patterns may be seen that are difficult to interpret. If tumor cell pattern is neither normal nor clearly amplified, test should be submitted for expert opinion.

- Should ensure that any specimen used for HER2 testing (cytologic specimens, needle biopsies, or resection specimens) begins the fixation process quickly (time to fixative within 1 hour) and is fixed in 10\% neutral buffered formalin for 6 to 72 hours and that routine processing, as well as staining or probing, is performed according to standardized analytically validated protocols.

- Should ensure that the laboratory conforms to standards set for CAP accreditation or an equivalent accreditation authority, including initial test validation, ongoing internal quality assurance, ongoing external proficiency testing, and routine periodic performance monitoring.

- If an apparent histopathologic discordance is observed in any HER2 testing situation (Table 2), the pathologist should consider ordering additional HER2 testing and conferring with the oncologist, and should document the decision-making process and results in the pathology report. As part of the HER2 testing process, the pathologist may pursue additional HER2 testing without conferring with the oncologist.

- Although categories of HER2 status by IHC or ISH can be created that are not covered by these definitions, in practice they are uncommon and if encountered should be considered IHC equivocal or ISH equivocal. 


\section{The Bottom Line (Continued)}

\section{Methods}

- Systematic review and analysis of the medical literature were conducted by the 2013 Update Committee.

\section{Additional Information}

- The revised recommendations and a brief summary of the literature and analysis are provided in this article. Data Supplements including clinical tools and resources can be found at http://www.asco.org/guidelines/her2 and at http://www.cap.org. Patient information is available at http://www.cancer.net. ASCO and CAP believe that cancer clinical trials are vital to inform medical decisions and improve cancer care, and that all patients should have the opportunity to participate.

expression reverse-transcriptase polymerase chain reaction, have been introduced into practice, and the Update Committee felt these required evidence-based review. The Update Committee wishes to re-emphasize that it is important that any new test methodology, for the same clinical use, be compared with a reference test that assays for the same analyte and for which there are high levels of evidence that use of the test leads to clinical benefit for the patient (ie, clinical utility). It is the opinion of the Update Committee that there is insufficient evidence to support use of mRNA or DNA microarray assays to determine HER2 status in unselected patients (Data Supplement 2A).

Further experience with established HER2 assays also led to the identification of unusual HER2 genotypic abnormalities, like aneusomy of chromosome 17 (polysomy and monosomy), colocalization of HER2 and CEP17 signals that affect HER2/CEP17 ratio in dual-signal in situ hybridization (ISH) assays, and genomic heterogeneity. Limited retrospective data on the clinical significance of these abnormalities in completed prospective trials also guided the discussions that were part of this guideline update. ${ }^{6-22}$ Some of these issues are discussed in Data Supplements $2 \mathrm{~B}$ and $2 \mathrm{C}$ and in a separate review article by Hanna et al. ${ }^{23}$

During the deliberations, the Update Committee was concerned about false-negative and false-positive HER2 assessments. For example, a false-negative test result could lead to denial of trastuzumab treatment for a patient who could benefit from it. False-positive results could lead to the administration of potentially toxic, costly, and ineffective adjuvant HER2-targeted therapy for 1 year. ${ }^{24-27}$ The Update Committee considered mandatory testing of all HER2negative tests (Data Supplement 2D) and addressed also a narrower set of scenarios that may on occasion be observed with dual-signal ISH assays (Data Supplement 2E; Interpretation Criteria If Using a Dual-Signal HER2 Assay and Average HER2 Copy Number <6 Signals Per Cell).

Trastuzumab had previously been shown to improve progression-free survival and overall survival when combined with chemotherapy in the metastatic setting. ${ }^{28}$ Since 2005, several of the first-generation adjuvant trials have been updated and have confirmed the disease-free and overall survival benefit offered by 1 year of trastuzumab administered with or after adjuvant chemotherapy. ${ }^{29-31}$ Prospective randomized trials, first reported in abstract form in late 2012, seem to suggest that 12 months is the optimal duration of adjuvant trastuzumab therapy.

Other HER2-targeted drugs (eg, the kinase inhibitor lapatinib, ${ }^{32}$ the antibody pertuzumab, ${ }^{33}$ and the antibodydrug conjugate ado-trastuzumab emtansine [T-DM1] ${ }^{34}$ ) have been approved for the treatment of HER2-positive metastatic breast cancer. At the same time, data show that lapatinib (when added to paclitaxel) ${ }^{35}$ and pertuzumab (as a single agent) ${ }^{36}$ offer no clinical benefit in patients with HER2-negative metastatic disease. These new HER2-targeted drugs are now being tested in the adjuvant setting, including in studies evaluating their adjuvant role alone or in dual-antibody regimens without concomitant or sequential chemotherapy. Compared with regimens already in use, the newer agents are as or more expensive, and they may be associated with other dose-limiting toxicities, such as skin and GI tract toxicities with lapatinib and liver toxicities with ado-trastuzumab emtansine. ${ }^{37}$

Therefore, the need for an updated ASCO/CAP guideline on accurate HER2 testing to ensure that the right patient receives the right treatment is now more critical than ever. ${ }^{22,24-27,38}$ Since the publication of the 2007 HER2 testing guideline, CAP has observed a remarkable uptake of proficiency testing (Fig 4), ${ }^{5}$ with nearly 1,500 laboratories currently participating. CAP has also observed fewer laboratories experiencing deficiencies on laboratory inspection. Indirect evidence suggests that the performance of laboratories that conduct HER2 testing in the United States and elsewhere is improving. ${ }^{39-42}$ Available evidence and experience since 2007 reinforce the importance of robust validation of new assays by laboratories before clinical implementation, as well as their ongoing monitoring, and the value of various external quality assurance schemes adopted in many countries.

\section{METHODS}

The HER2 testing Update Committee (Appendix Table A1, online only at www.asco.org/guidelines/her2) met 3 times via Webinars coordinated by its Steering Committee to review the data published from January 2006 to January 2013 and to revise the recommendations. Additional data were gathered from in-press publications and personal correspondence with researchers to address the issue of mandatory testing if a test result is 0 or $1+$. Draft manuscripts were circulated by e-mail, and the Update Committee approved the final manuscript. This guideline was reviewed by external reviewers and approved by the ASCO Clinical Practice Guideline Committee and relevant CAP entities.

\section{Literature Search Strategy}

The MEDLINE and the Cochrane Collaboration Library electronic databases were searched with the date parameters of January 2006 through January 2013 for articles in English. The MEDLINE search terms are included in Data Supplement 3, and a summary of the literature search results is provided in Data Supplement 4.

\section{Inclusion and Exclusion Criteria}

Articles were selected for inclusion in the systematic review of the evidence if they met the following criteria: (1) the study compared, prospectively or retrospectively, fluorescent ISH (FISH) and immunohistochemistry (IHC) results or other tests; described technical comparisons across various assay platforms; examined potential testing algorithms for HER2 testing; or examined the 
correlation of HER2 status in primary versus metastatic tumors from the same patients; (2) the study population consisted of patients with a diagnosis of invasive breast cancer; or (3) the primary outcomes included the negative predictive value (NPV) or positive predictive value (PPV) of ISH and IHC assays used to determine HER2 status, alone and in combination; negative and positive concordance across platforms; and accuracy in determining HER2 status and benefit from anti-HER2 therapy and in determining sensitivity and specificity of individual tests. Consideration was given to studies that directly compared results across assay platforms.

Studies were not limited to randomized controlled trials but also included other study types, including cohort designs, case series, evaluation studies, and comparative studies. The Update Committee also reviewed other testing guidelines and proficiency strategies of various US and international organizations, including unpublished data. Letters, commentaries, and editorials were reviewed for any new information. Case reports were excluded. The clinical questions addressed in the update are available in Data Supplement 5.

This information was used to help the Update Committee develop new algorithms (for pathologists and oncologists) for testing, specify testing requirements and exclusions, and facilitate the necessary quality assurance monitoring that will make HER2 testing less variable and ensure more analytic consistency between laboratories. The term ratio, as used in the guideline recommendations and algorithms, always applies to the HER2/CEP17 ratio, which means the ratio of HER2 signals per cell (numerator) over CEP17 signals per cell (denominator).

\section{ASCO Guideline Disclaimer}

The clinical practice guideline and other guidance published herein are provided by ASCO to assist practitioners in clinical decision making. The information herein should not be relied on as being complete or accurate, nor should it be considered as inclusive of all proper treatments or methods of care or as a statement of the standard of care. With the rapid development of scientific knowledge, new evidence may emerge between the time information is developed and when it is published or read. The information is not continually updated and may not reflect the most recent evidence. The information addresses only the topics specifically identified herein and is not applicable to other interventions, diseases, or stages of diseases. This information does not mandate any particular course of medical care. Furthermore, the information is not intended to substitute for the independent professional judgment of the treating physician, because the information does not account for individual variation among patients. Recommendations reflect high, moderate, or low confidence that the recommendation reflects the net effect of a given course of action. The use of terms like must, must not, should, and should not indicate that a course of action is recommended or not recommended for either most or many patients, but there is latitude for the treating physician to select other courses of action in individual cases. In all cases, the selected course of action should be considered by the treating physician in the context of treating the individual patient. Use of the information is voluntary. ASCO provides this information on an as-is basis and makes no warranty, express or implied, regarding the information. ASCO specifically disclaims any warranties of merchantability or fitness for a particular use or purpose. ASCO assumes no responsibility for any injury or damage to persons or property arising out of or related to any use of this information or for any errors or omissions.

\section{CAP Guideline Disclaimer}

Clinical practice guidelines reflect the best available evidence and expert consensus supported in practice. They are intended to assist physicians and patients in clinical decision making and to identify questions and settings for further research. With the rapid flow of scientific information, new evidence may emerge between the time a practice guideline or consensus statement is developed and when it is published or read. Guidelines and statements are not continually updated and may not reflect the most recent evidence.
Guidelines and statements address only the topics specifically identified therein and are not applicable to other interventions, diseases, or stages of diseases. Furthermore, guidelines and statements cannot account for individual variation among patients and cannot be considered inclusive of all proper methods of care or exclusive of other treatments. It is the responsibility of the treating physician, relying on independent experience and knowledge, to determine the best course of treatment for the patient. Accordingly, adherence to any practice guideline or consensus statement is voluntary, with the ultimate determination regarding its application to be made by the physician in light of each patient's individual circumstances and preferences. CAP makes no warranty, express or implied, regarding guidelines and statements and specifically excludes any warranties of merchantability and fitness for a particular use or purpose. CAP assumes no responsibility for any injury or damage to persons or property arising out of or related to any use of this statement or for any errors or omissions.

\section{Guideline and Conflicts of Interest}

The Update Committee was assembled in accordance with CAP and ASCO Conflicts of Interest Management Procedures for Clinical Practice Guidelines (ASCO procedures are summarized at http://www.asco.org/guidelinescoi). Members of the Update Committee completed the ASCO disclosure form, which requires disclosure of financial and other interests that are relevant to the subject matter of the guideline, including relationships with commercial entities that are reasonably likely to experience direct regulatory or commercial impact as the result of promulgation of the guideline. Categories for disclosure include employment relationships, consulting arrangements, stock ownership, honoraria, research funding, and expert testimony. In accordance with the procedures, the majority of the members of the Update Committee did not disclose any such relationships.

\section{RECOMMENDATIONS}

\section{CLINICAL QUESTION 1}

What is the optimal testing algorithm for the assessment of HER2 status?

\section{Literature Update and Discussion}

The Update Committee found more than 70 new publications that informed a revision of the testing algorithms contained in the original 2007 guideline. At the time of the original guideline, significant concern existed about falsepositive HER2 test results. Guideline recommendations emphasized those changes that would mitigate false positives, particularly relating to issues of specimen fixation and pathologist interpretation. ${ }^{39,43-47}$ Preliminary data from an ongoing prospective study seem to suggest that the frequency of false-positive test results may have diminished, in that the concordance between local testing in laboratories throughout the United States and confirmatory central HER2 testing at the Mayo Clinic (Rochester, MN) for the ALTTO (Adjuvant Lapatinib and/or Trastuzumab Treatment Optimization HER2 Adjuvant Trial) trial showed that less than 6\% of patients initially considered eligible were not subsequently centrally confirmed as being HER2 positive. $^{48}$

On the other end of the spectrum, clinical experience and recent literature have indicated that false-negative HER2 test results must also be considered. The Update Committee was sensitive to the concerns that surfaced after the publication of the 2007 guideline about the very small number of patients potentially affected by the recommendation to consider as HER2 positive only those tumors with more than $30 \%$ of cells (or $>10 \%$ to $\leq 30 \%$ if HER2 amplified by FISH) with diffuse and intense circumferential staining. ${ }^{49}$ Therefore, the 
Update Committee decided to revert to the previously used IHC criterion of more than 10\% cells staining for HER2, which had been used as an entry criterion for eligibility for the first generation of prospective randomized trials of adjuvant trastuzumab. ${ }^{18,22,49-53}$ The rationale for this recommendation by the Update Committee is detailed in Data Supplement 1 . Aside from the very small number of patients affected (as few as $0.15 \%$ of all newly diagnosed patients, as previously discussed), ${ }^{5}$ the Update Committee was also of the opinion that improvements in analytic performance of HER2 testing in clinical practice since 2007 have further reduced the already small number of patients potentially at risk of receiving a false-negative test result.

Testing is now recommended for primary, recurrent, and metastatic tumors. ${ }^{19,35,45,54-63,64}$ Tissue from the primary tumor can be obtained through a core needle biopsy, as well as from an incisional and excisional surgical procedure. ${ }^{65}$ Metastases can be biopsied from chest wall, regional lymph nodes, or distant organs. ${ }^{6-74}$ It is essential to ensure that time to fixation (cold ischemic time) and time in fixative (which has increased from 6 to 48 hours to 6 to 72 hours in this update on the basis of available data and to conform with the ASCO/CAP estrogen receptor [ER]/progesterone receptor $[\mathrm{PgR}]$ testing guideline $\mathrm{e}^{75,76}$ ) are recorded and considered in defining the test result. More detail about preanalytic issues is available in Data Supplement 6.

In summary, if available, perform the first test in the core biopsy specimen in a patient with newly diagnosed breast cancer. If the test result is clearly positive or clearly negative as defined in Table 1, no retesting is needed. If the test is negative and there is apparent histopathologic discordance (Table 2), or if specimen handling has not been in accordance with guideline recommendations, a section of the tumor from the excisional specimen should be tested. If this result is positive, no further testing is needed. However, if the test is negative and there remains significant clinical concern about the result after consultation between the pathologist and the medical oncologist, it may be appropriate to repeat the test in a different block from the patient's tumor. If all three tests are negative, no additional testing is recommended.

Data Supplement 7 is a table of IHC Interpretation Criteria, and Data Supplement 8 provides ISH Interpretation Criteria. Both of these Data Supplements expand on details provided in Table 1.

The Update Committee clarified several issues in the update on the basis of recently published literature. The recommendations in Table 1 reflect the Update Committee's interpretation of the new data on polysomy, heterogeneity in ISH, types of assays, and methods of analysis ${ }^{10-14,19-21,45,67,69,79-135}$ for inclusion in this update. See Data Supplement 2 for an extensive discussion of these issues.

A list of US Food and Drug Administration (FDA) approved assays is available at http://www.accessdata.fda.gov/scripts/ $\mathrm{cdrh} /$ devicesatfda/index.cfm?start_search $=1 \&$ search_term $=$ HER2\&approval_date_from=\&approval_date_to $=07 / 14 /$ 2013\&sort=approvaldatedesc\&pagenum $=10$ (last checked July 14, 2013). The product package inserts for trastuzumab and pertuzumab prepared by the FDA indicate that "HER2 testing should be performed using US Food and Drug Administration-approved tests by laboratories with demonstrated proficiency."177,78

Arch Pathol Lab Med—Vol 138, February 2014

\section{HER2 Assay Exclusions}

Each assay type has diagnostic pitfalls to be avoided. The Update Committee agreed that there were situations in which one assay type was preferred because of assay or sample considerations. Exclusion criteria to perform or interpret an IHC or any ISH assay for HER2 are unchanged but can be viewed in the original guideline. ${ }^{1,2}$ The pathologist who reviews the histologic findings should determine the optimal assay (IHC or ISH) for determination of HER2 status.

\section{Algorithms for HER2 Testing by IHC and ISH}

Algorithms for evaluation of HER2 protein expression by IHC and HER2 amplification by single-probe or dual-probe ISH are presented in Figures 1, 2, and 3.

\section{CLINICAL QUESTION 2}

What strategies can help ensure optimal performance, interpretation, and reporting of established assays?

\section{Literature Update and Discussion}

Testing analytic validation requirements. - The Update Committee reviewed new papers and reports on strategies to ensure optimal performance, interpretation, and reporting of assays. ${ }^{16,22,100,136,137}$ Most new HER2 assays have been submitted to the FDA for premarket approval review as class III devices in view of their use for therapy selection. Although a new HER2 assay ideally should have its clinical utility validated using specimens from prospective therapeutic trials that tested the effects of anti-HER2 therapy, the Update Committee recognizes that the rarity of these valuable specimens requires that new HER2 assays be approved on the basis of concordance studies comparing them with other established HER2 tests. Consequently, it is important that tissues selected for such concordance studies come from datasets that include a broad representation of patients with breast cancer in whom HER2-positive status will be observed in approximately $15 \%$ to $20 \%$.

Ongoing competency assessment.-The Update Committee urges ongoing competency assessment as a part of every laboratory's internal quality assessment program. The competency of the laboratory professionals and pathologists interpreting assays must be continuously addressed as required under the Clinical Laboratory Improvements Amendments (CLIA 88). The acceptable performance standard for such competency tests remains the same as in the original guideline.

Reporting requirements.-Data Supplements 9 and 10 are tables of reporting elements for IHC and reporting elements for ISH, respectively. Some changes have been made to the reporting elements for IHC and ISH to ensure that they are in accordance with the revised recommendations. In addition, a disclaimer statement is required if the specimen handling requirements are not met.

New interpretation requirements relate to the definition of tumor samples with genomic heterogeneity as well as the examination of specimens and interpretation of results in these samples. No specific requirements were added for designation of polysomy by ISH. Laboratories should maintain documentation of their quality assurance practices and ensure that such documentation is available for inspection.

Regulatory framework.-The regulatory framework remains the same as discussed in the original guideline. 


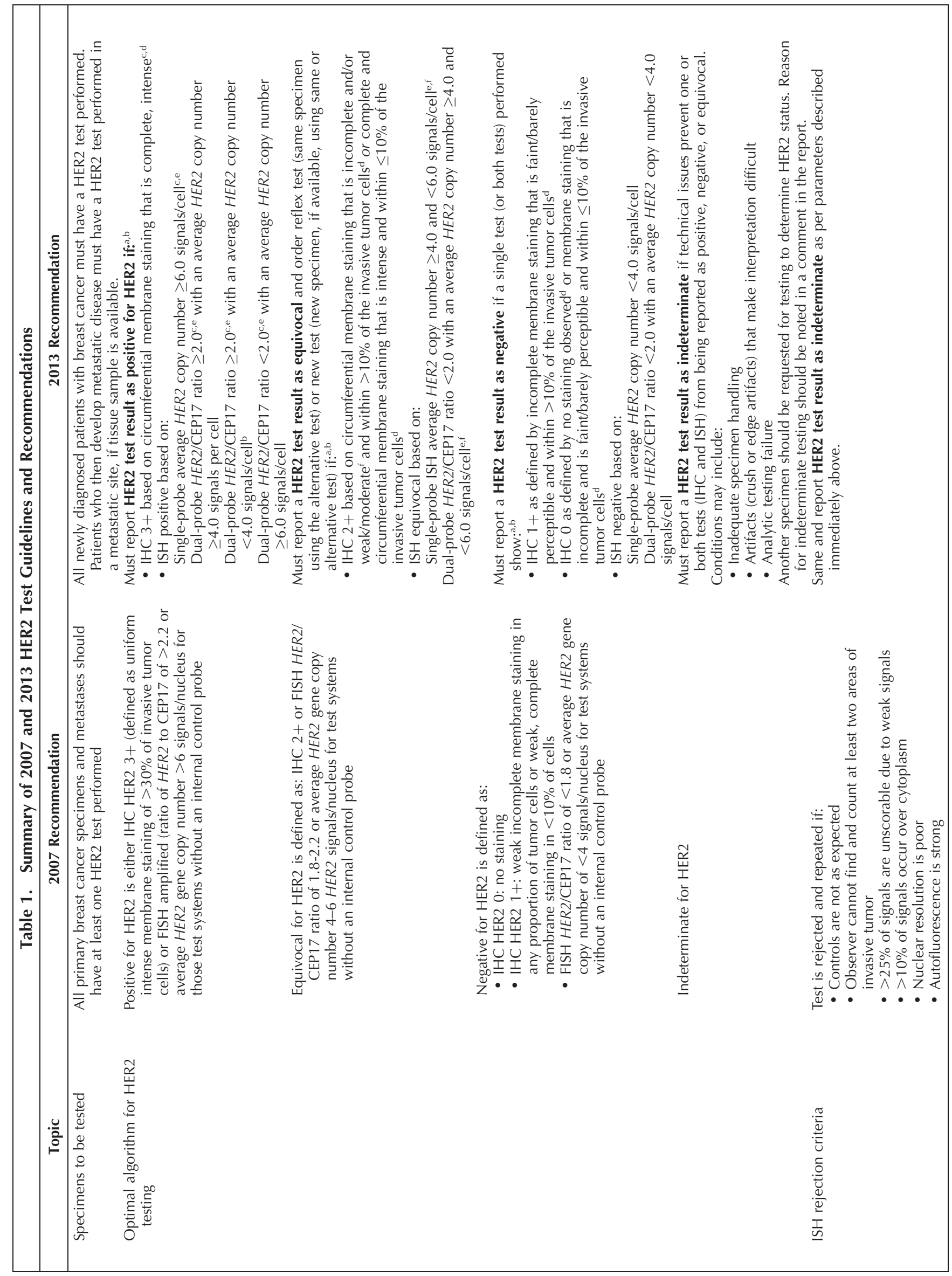




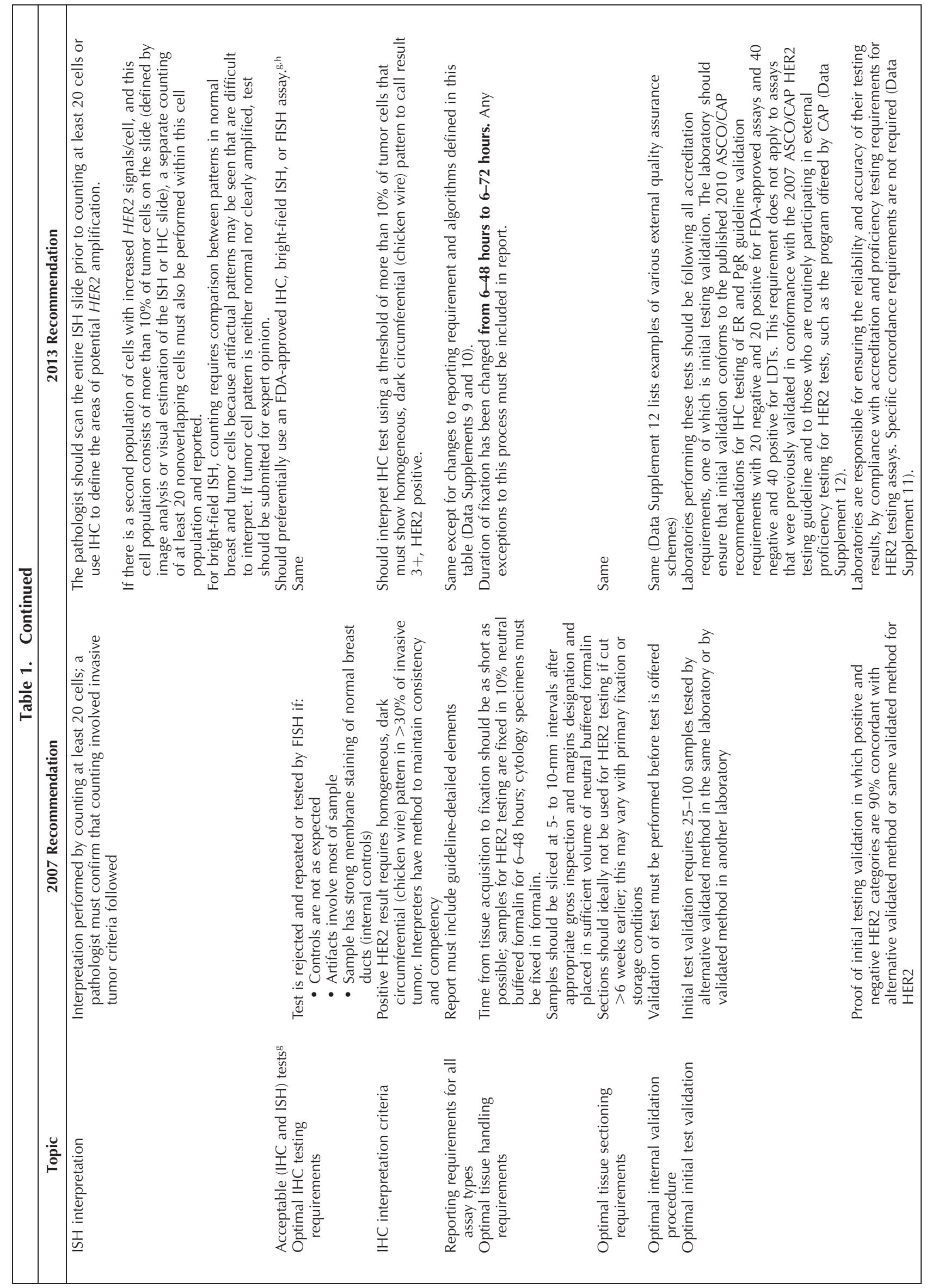




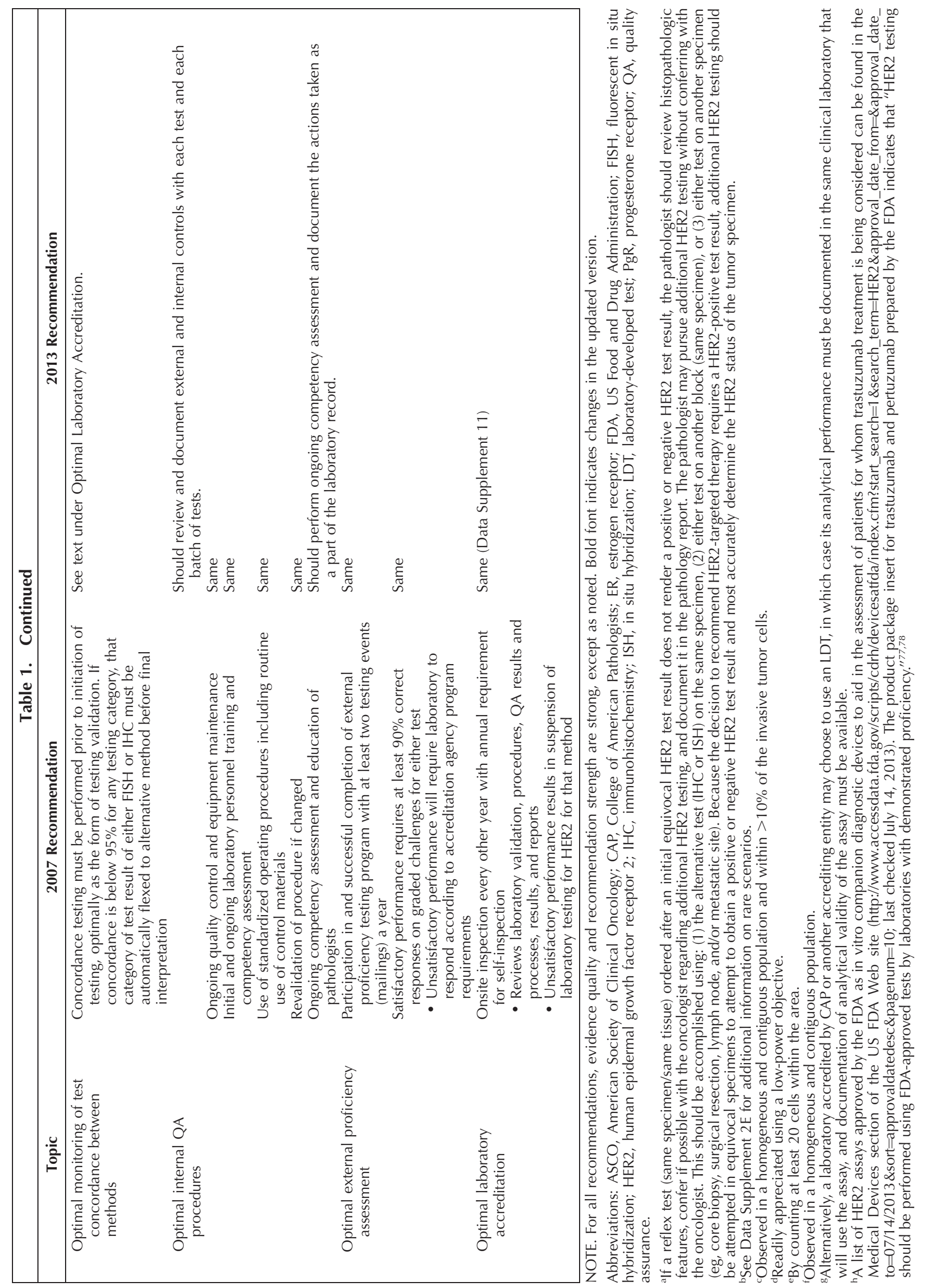




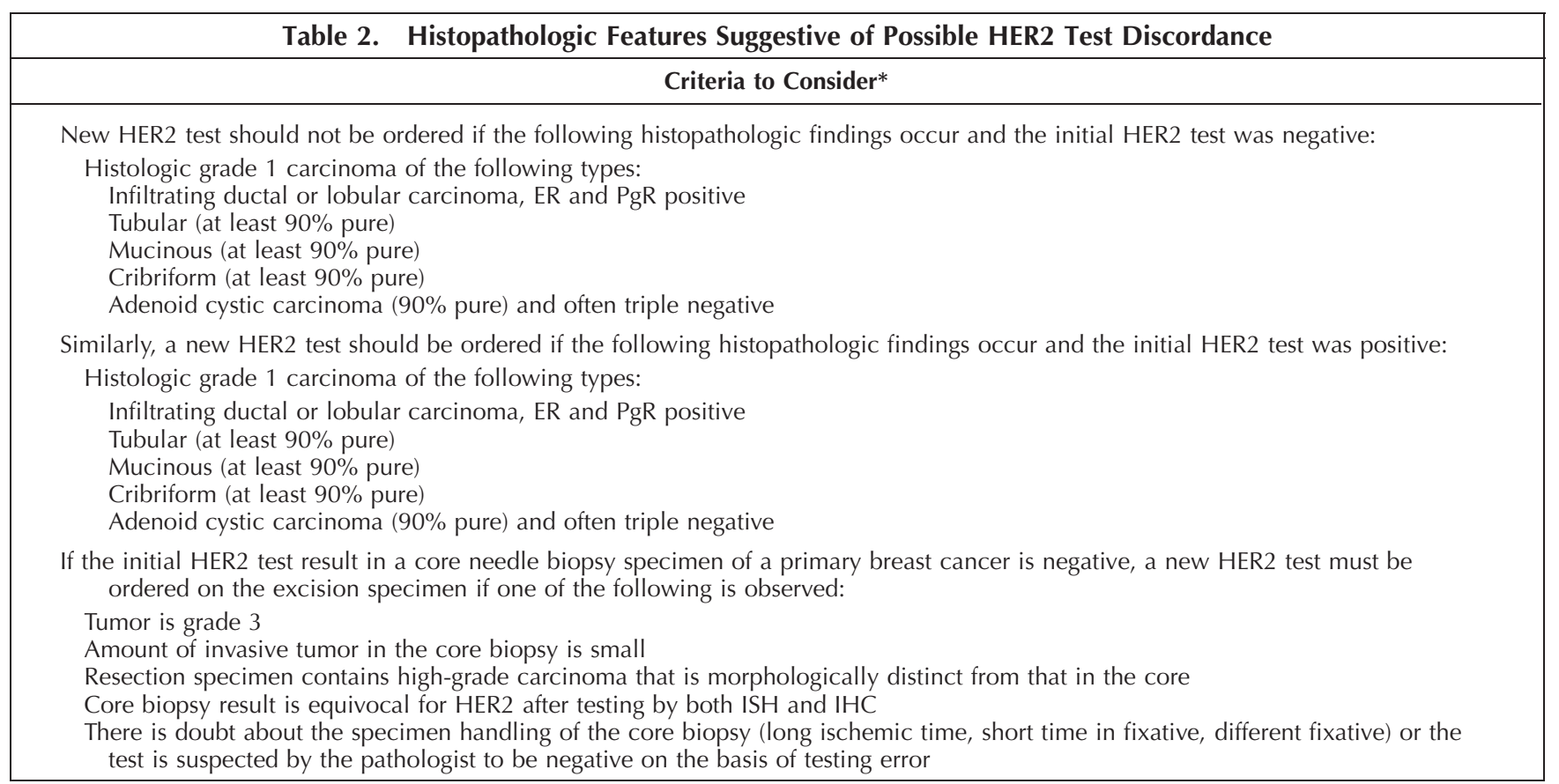

Abbreviations: ER, estrogen receptor; HER2, human epidermal growth factor receptor 2; IHC, immunohistochemistry; ISH, in situ hybridization; PgR, progesterone receptor.

${ }^{*}$ Criteria to consider if there are concerns regarding discordance with apparent histopathologic findings and possible false-negative or false-positive HER2 test result.

At the current time, the FDA exercises enforcement discretion over laboratory-developed tests (LDTs) that are generated and performed within an individual laboratory under CLIA 88. CLIA 88 provides stringent quality standards for highly complex tests, which include all predictive cancer factor assays. This legislation also requires biannual surveys of laboratories that perform highly complex tests, with defined criteria and actions required when performance is deficient. However, CLIA certification does not require that the tests performed have been shown with a high level of evidence to have clinical utility. ${ }^{138,139}$ Moreover, FDA approval of devices, which includes in vitro diagnostic tests such as those discussed in this guideline, does not necessarily require demonstration that use of the assay results in improved clinical outcomes compared with not using the assay. The Update Committee expresses concern about the need for greater clarity in the regulatory environment with regard to companion diagnostic tests and LDTs for higher-risk tumor biomarker tests, such as HER2. Some of this has been discussed by the Evaluation of Genomic Applications in Practice and Prevention (EGAPP) Initiative and endorsed by the Institute of Medicine Committee in regard to omics-based tests, as well as others, ${ }^{139}$ and the Update Committee understands the FDA is developing a risk-based framework to address concerns about test accuracy and clinical utility.

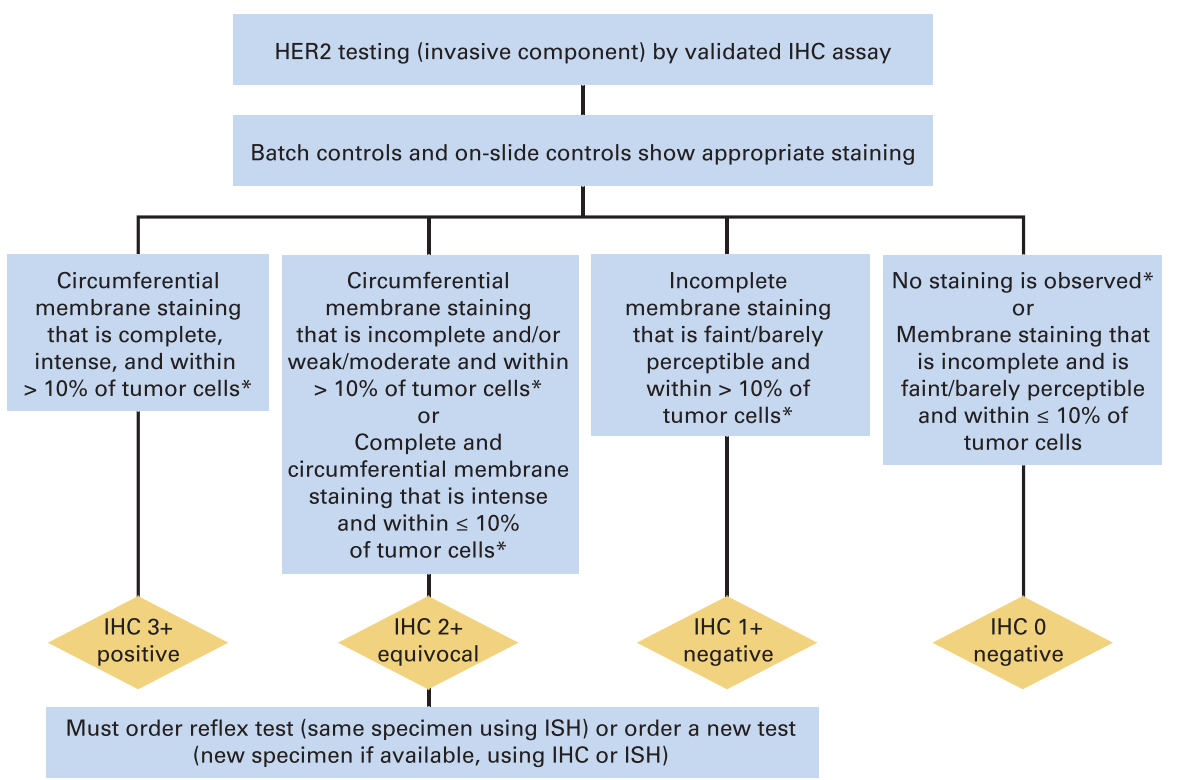

Figure 1. Algorithm for evaluation of human epidermal growth factor receptor 2 (HER2) protein expression by immunohistochemistry (IHC) assay of the invasive component of a breast cancer specimen. Although categories of HER2 status by IHC can be created that are not covered by these definitions, in practice they are rare and if encountered should be considered IHC $2+$ equivocal. ISH, in situ hybridization. NOTE: the final reported results assume that there is no apparent histopathologic discordance observed by the pathologist. (*) Readily appreciated using a low-power objective and observed within a homogeneous and contiguous invasive cell population. 
Figure 2. Algorithm for evaluation of human epidermal growth factor receptor 2 (HER2) gene amplification by in situ hybridization (ISH) assay of the invasive component of a breast cancer specimen using a single-signal (HER2 gene) assay (single-probe ISH). Amplification in a single-probe ISH assay is defined by examining the average HER2 copy number. If there is a second contiguous population of cells with increased HER2 signals per cell, and this cell population consists of more than $10 \%$ of tumor cells on the slide (defined by image analysis or visual estimation of the ISH or immunohistochemistry [IHC] slide), a separate counting of at least 20 nonoverlapping cells must also be performed within this cell population and also reported. Although categories of HER2 status by ISH can be created that are not covered by these definitions, in practice they are rare and if encountered should be considered ISH equivocal (see Data Supplement 2E). NOTE: the final reported results assume that there is no apparent histopathologic discordance observed by the pathologist. (*) Observed in a homogeneous and contiguous population.

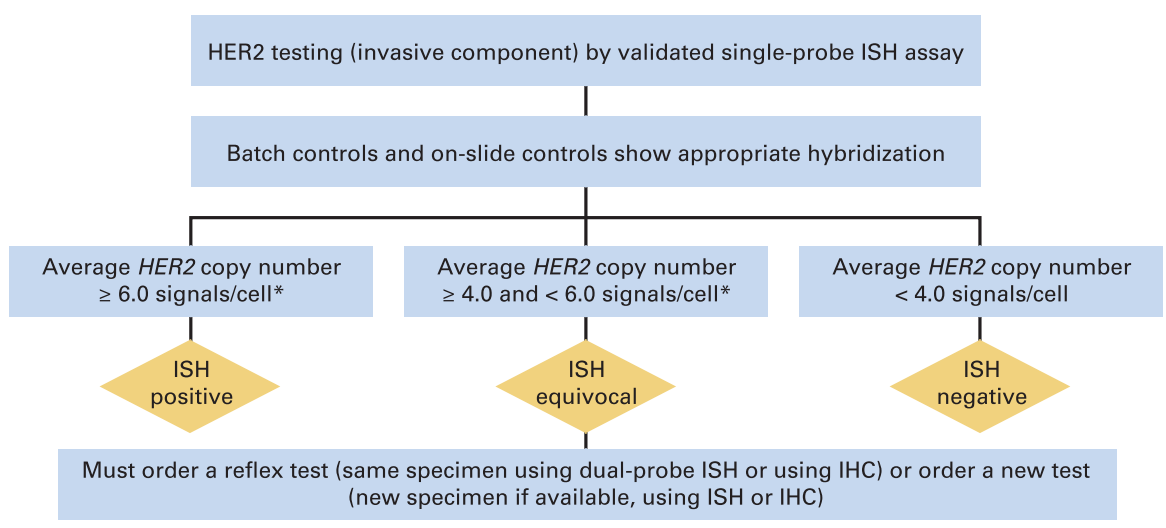

concordance between local and central laboratories, both in the United States and internationally. ${ }^{40,51,136,140-146}$ A revised table addressing proficiency testing is contained in Data Supplement 11, which describes statistical requirements for proficiency testing. Examples of international external quality assurance schemas are included in Data Supplement 12.

The number of laboratories participating in predictive marker proficiency testing for HER2 and ER as part of the CAP laboratory improvement program since 2004 is shown in Figure 4, and the program is described at http://www.cap. org/apps/cap.portal?_nfpb=true\&_pageLabel=accreditation (last checked July 14, 2013).
Figure 3. Algorithm for evaluation of human epidermal growth factor receptor 2 (HER2) gene amplification by in situ hybridization (ISH) assay of the invasive component of a breast cancer specimen using a dual-signal (HER2 gene) assay (dual-probe ISH). Amplification in a dual-probe ISH assay is defined by examining first the HER2/CEP17 ratio followed by the average HER2 copy number (see Data Supplement 2E for more details). If there is a second contiguous population of cells with increased HER2 signals per cell, and this cell population consists of more than $10 \%$ of tumor cells on the slide (defined by image analysis or visual estimation of the ISH or immunohistochemistry [IHC] slide), a separate counting of at least 20 nonoverlapping cells must also be performed within this cell population and also reported. Although categories of HER2 status by ISH can be created that are not covered by these definitions, in practice they are rare and if encountered should be considered ISH equivocal (see Data Supplement 2E). NOTE. The final reported results assume that there is no apparent histopathologic discordance observed by the pathologist. (*) Observed in a homogeneous and contiguous population. $(t)$ See Data Supplement $2 E$ for more information on these rare scenarios.

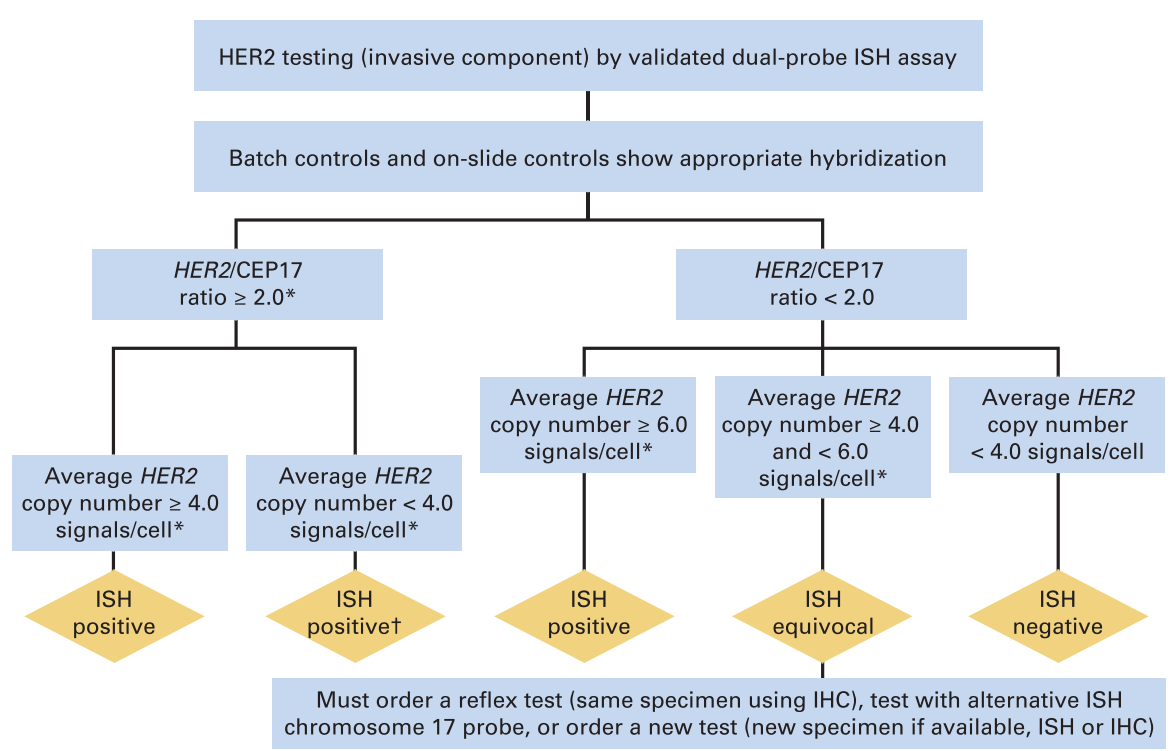




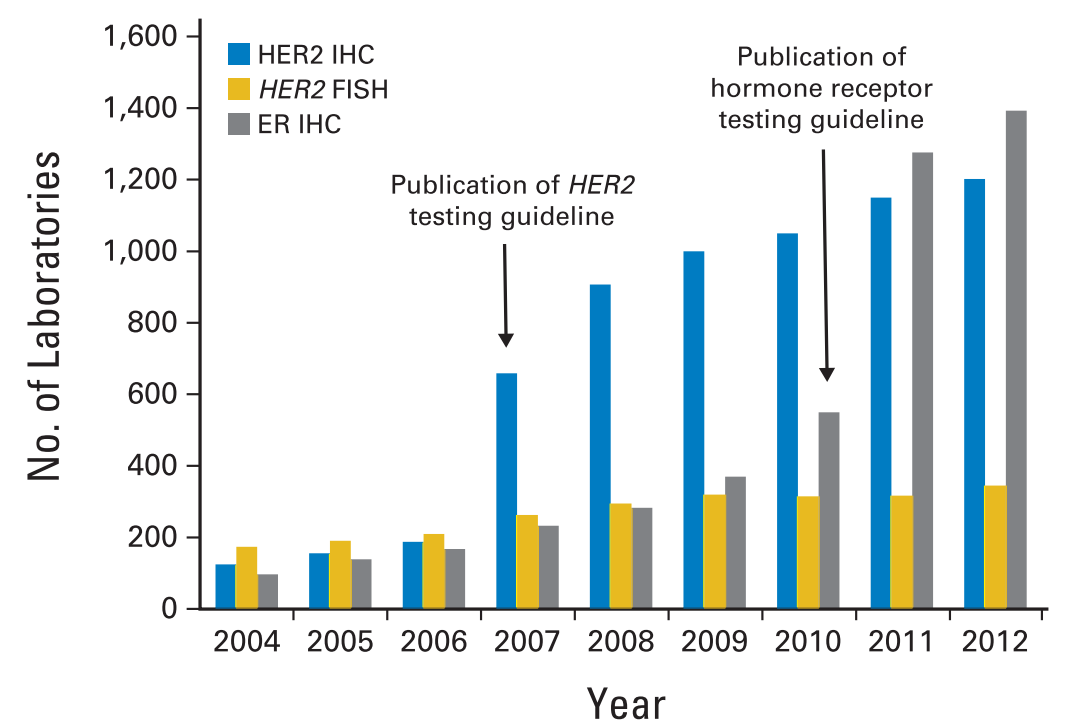

Figure 4. Number of laboratories participating in predictive marker proficiency testing for human epidermal growth factor receptor 2 (HER2) by immunohistochemistry (IHC), HER2 by fluorescent in situ hybridization (FISH), and estrogen receptor (ER) by IHC through the College of American Pathologists (CAP) Laboratory Improvement Program. Arrows indicate the years during which the HER2 and hormone receptor testing guidelines were published by the American Society of Clinical Oncology (ASCO)/CAP. The numbers of participating laboratories are shown both graphically and in tabular form. After the publication of the 2007 ASCO/CAP HER2 and the 2010 ASCO/CAP ER/progesterone receptor testing guidelines, there was a significant increase in the number of laboratories in the United States and elsewhere participating in CAP proficiency testing surveys in breast cancer (http://www.cap.org/ apps/cap.portal?_nfpb=true\&_pageLabel =accreditation; last checked June 14, 2013). CAP has a core goal to improve the quality of pathology and laboratory services through education and standard setting in order to enhance patient safety, and help laboratories meet or exceed regulatory requirements set by the Centers for Medicare and Medicaid Services, the Joint Commission, and many states in the United States.

\section{Ongoing Communication, Education, and Evaluation Efforts by CAP}

CAP has undertaken comprehensive efforts to educate pathologists about ways to improve laboratory performance of HER2, ER, and PgR assays. Numerous live and online educational offerings are available from CAP and other organizations. Examples in North America include the American Society of Clinical Pathology (ASCP) and United States and Canadian Academy of Pathology (USCAP). CAP provides varied live and online education focused on HER2 and $\mathrm{ER} / \mathrm{PgR}$ testing elements of relevance to pathologists in meeting the original ASCO/CAP HER2 and ER/PgR guidelines and updates. In follow-up surveys, participants routinely report they made changes to their practice as a result of the educational experience. Many of these learning opportunities have a scored assessment component, allowing participants to test their knowledge as part of completing the courses, and can be used to meet the American Board of Pathology (ABP), the US pathologist certifying organization, Maintenance of Certification requirements. More information can be found at the CAP learning portal (http://www.cap.org) and in the original guideline. CAP has also created a listing of competencies in breast pathology, compiled by experts and available for pathologist self-assessment. After taking this self-assessment, pathologists are prompted to learning offerings that target those areas of self-reported educational deficiency. A listing of the courses is available online at http://www.cap. org via the learning portal.

\section{STUDY QUALITY, LIMITATIONS OF THE LITERATURE, AND FUTURE RESEARCH}

Whether in the context of trastuzumab clinical trials or of studies comparing HER2 testing platforms, interpretation of the literature in the field of HER2 testing is still complicated by a lack of standardization across trials in assay utilization and interpretation, presence or absence of confirmatory testing, and local versus central laboratory testing, among other considerations. Although FDA-approved assays have been carefully validated, not all LDTs may have, which complicates direct comparisons across trials and platforms, and we maintain that this situation leaves open the possibility that a substantial percentage of some patients with breast cancer could be either over- or undertreated with HER2-targeted therapies.

An important gap in the literature identified by the Update Committee concerns those patients with test results reported as equivocal. The decision to treat with specific therapies like trastuzumab is by necessity dichotomous (yes or no) and will not be informed by an equivocal diagnosis with respect to HER2 status without repeat testing, if possible. However, HER2 test results are derived from a continuous variable, which can be expected to lead to some results falling into a gray area. Adding to this confusion is the fact that there is variability in the reporting definitions of the equivocal ranges for both bright-field ISH and FISH assays.

The literature is lacking evidence on response to HER2targeted therapy in the subgroup of patients with equivocal results, and there are limited efficacy data in the subgroup tested with both high quality IHC and FISH and found to have a discordant result between these two tests. Patients with such results constitute poorly studied subsets for which there is less confidence in the scores and actual benefit from trastuzumab therapy. Because the retrospective evaluation of the benefit from trastuzumab in patients with apparent discordance between IHC and FISH who were enrolled onto the first generation of trastuzumab trials included only a small number of patients in each of the discordant subsets, patients who would have qualified for enrollment in those trials should be considered for HER2-targeted therapy.

The Update Committee's goal was to address the most common clinical situations encountered by pathologists and 
oncologists in routine clinical practice. Specifically in regard to ISH assays, it expected that additional but rare categories of HER2 status by ISH could be created that are not covered by the definitions illustrated in Figures 2 and 3. Data Supplement 2E addresses a narrower set of scenarios that may on occasion be observed with dual-signal ISH assays.

For patients with low levels of HER2 expression that do not reach the threshold for HER2-positive disease, the Update Committee encourages enrollment of such patients, if eligible, onto prospective clinical trials that aim to address the value of adjuvant HER2-targeted therapies in patients whose breast cancers show low levels of HER2 expression, like the NSABP B-47 (National Surgical Adjuvant Breast and Bowel Project B-47) trial (NCT01275677). The Update Committee also supports participation in studies evaluating other cutoffs and other technologies to optimize eligibility for HER2-targeted therapies.

\section{PATIENT AND CLINICIAN COMMUNICATION}

Patients (and family members or caregivers) should be educated about the results of pathology tests and how they are used to develop a treatment plan tailored to the biology of their cancers. Because many newly diagnosed patients are under emotional stress and/or may be unaccustomed to complex medical terminology, the use of easily understood language (at an educational level that the patient can understand) is key to clear communication. Asking patients to repeat back key pieces of information, providing written or recorded notes, and using visual aids can help ensure information is effectively communicated.

Patients should be given a copy of their pathology report and HER2 test results. The clinician should review the results with the patient, discuss any issues with the test interpretation or performance, and ask if he or she has any additional questions about the results.

\section{Key Points for Clinicians to Discuss With Patients Regarding HER2 Status}

Explain the importance of determining the biologic characteristics of breast cancer.-Patients should understand that the most common biologic tests are those for ER, PgR, and HER2 and that testing for these markers is important to select an appropriate treatment. The overall percentage of patients with HER2-positive breast cancer is between $15 \%$ and $20 \%$. Observed numbers may vary depending on the population being tested by individual laboratories.

Explain the importance of HER2 testing.-Patients should understand that HER2 status determines whether certain drugs (eg, trastuzumab, lapatinib, pertuzumab, TDM1) are recommended. They should also understand that the HER2 gene is important in tumor cell growth and that tumors that have increased levels of HER2 (as measured by HER2 gene amplification or HER2 protein overexpression) usually have a higher growth rate and a more aggressive clinical behavior.

Explain the type of tissue used for HER2 testing.Patients should understand the type of tissue used for HER2 testing (eg, core biopsy, excisional biopsy).

Explain the types of tests used to determine HER2 status.-Patients should understand that there are different FDA-approved testing methods that detect HER2 protein overexpression or the presence of HER2 gene amplification.
Explain the interpretation of the HER2 test results.Patients should understand that although most HER2 test results are definitively positive or negative, there are equivocal results that require additional testing using an alternative test or using the same or alternative test on a different portion of the same specimen (different block). Sometimes, the oncologist or pathologist may recommend additional testing using a different type of tumor specimen (eg, surgical excision $v$ core biopsy), if available. Patients should be informed about which test or tests were performed and the expected turnaround time for these tests. Unfortunately, some results remain indeterminate or inconsistent with other histopathologic findings. In such cases, a final treatment decision to consider treatment with HER2-targeted therapy should be made after consultation between the pathologist and oncologist and a discussion with the patient.

Explain the importance of retesting HER2 status in new, metastatic tumors.-Patients should understand that HER2 status may occasionally be different (discordant) when comparing a previous primary tumor and a site of recurrence or in the setting of multiple simultaneous metastatic sites. In some cases, it is not possible to fully differentiate between a true biologic change, tumor heterogeneity, or variability in the performance of the assay.

Explain that HER2 testing guidelines exist.-Patients should be assured that HER2 testing guidelines were followed. Refer patients to the ASCO/CAP guideline update at www.asco.org/guideline/her2 and/or http://www.cap.org and to www.cancer.net for additional patient-focused information.

\section{HEALTH DISPARITIES}

Although ASCO clinical practice guidelines present recommendations on the best practices in diagnosis and disease management to provide the highest level of cancer diagnosis and care, it is important to note that some racial/ ethnic minority patients have limited access to optimal medical care and/or accredited pathology laboratories. At the same time, some Medicaid or uninsured patients may have access to accredited pathology laboratories by virtue of receiving some or all of their care in an academic medical center. ${ }^{147-150}$

Disparities clearly exist in the likelihood of receiving HER2 testing. In the United States, Lund et $\mathrm{al}^{151}$ used data from the National Cancer Institute Metropolitan Atlanta SEER Registry in conjunction with the Georgia Comprehensive Cancer Registry to examine HER2 testing among all cases of primary invasive breast cancer diagnosed among female residents during 2003 to 2004. Overall, 90.1\% of women had evidence of HER2 testing. Rates of HER2 testing did not vary significantly based on socioeconomic status (based on the percent living below the federal poverty level) and were similar between black (91.3\%) and white $(89.8 \%)$ women. This is in agreement with other reports showing similar or greater rates of HER2 testing among black versus white women with breast cancer. ${ }^{152}$ However, in the Lund et al study, Hispanic women were significantly less likely to receive HER2 testing $(79.3 \%)$, as were women diagnosed with stage IV $(80.7 \%)$ or unknown stage $(71.7 \%)$ disease. In addition, the mean age of women who received HER2 testing (58.8 years) was significantly younger than that of women who did not receive testing (61.3 years). Other studies have also reported that older women ${ }^{153,154}$ and those 
with distant disease are significantly less likely to have documentation of HER2 testing. Stark et a ${ }^{155}$ also reported that women with capitated insurance (versus fee-for-service insurance) were significantly more likely to be tested for HER2 status. Awareness of possible disparities in access to care should be considered in the context of this clinical practice guideline, and health care providers should strive to deliver the highest level of cancer care to these vulnerable populations.

\section{ADDITIONAL RESOURCES}

Data Supplements, including evidence tables, and clinical tools and resources can be found at www.asco.org/ guidelines/her2. Information for patients is available at http://www.cancer.net.

\section{AUTHORS' DISCLOSURES OF POTENTIAL CONFLICTS OF INTEREST}

Although all authors completed the disclosure declaration, the following author(s) and/or an author's immediate family member(s) indicated a financial or other interest that is relevant to the subject matter under consideration in this article. Certain relationships marked with a " $U$ " are those for which no compensation was received; those relationships marked with a " $C$ " were compensated. For a detailed description of the disclosure categories, or for more information about ASCO's conflict of interest policy, please refer to the Author Disclosure Declaration and the Disclosures of Potential Conflicts of Interest section in Information for Contributors.

Employment or Leadership Position: Donald C. Allred, Clarient-GE Healthcare (C) Consultant or Advisory Role: Mitch Dowsett, Roche (C); Donald C. Allred, Clarient (U); John M.S. Bartlett, Roche Canada (C), Roche UK (C); Michael Bilous, Roche (C); Wedad Hanna, Roche (C); Michael F. Press, Roche (C); Giuseppe Viale, Roche (C), Genomic Health (C), Dako (C) Stock Ownership: None Honoraria: Mitch Dowsett, Roche, Dako; John M.S. Bartlett, Roche Canada, Roche UK; Michael Bilous, Roche; Wedad Hanna, Roche; Giuseppe Viale, Roche Research Funding: Mitch Dowsett, Roche; John M.S. Bartlett, Roche UK; Wedad Hanna, Roche; Michael F. Press, Roche Expert Testimony: None Patents: None Other Remuneration: John M.S. Bartlett, Roche UK; Wedad Hanna, Roche; Robert B. Jenkins, Abbott.

\section{AUTHOR CONTRIBUTIONS}

Administrative support: Antonio C. Wolff, M. Elizabeth $\mathrm{H}$. Hammond, David G. Hicks, Mitch Dowsett, Lisa M. McShane, Pamela B. Mangu, Daniel F. Hayes

Manuscript writing: All authors

Final approval of manuscript: All authors

\section{AFFILIATIONS}

Antonio C. Wolff, Johns Hopkins Kimmel Comprehensive Cancer Center, Baltimore; Lisa M. McShane, National Cancer Institute, Bethesda, MD; M. Elizabeth H. Hammond, University of Utah School of Medicine and Intermountain Healthcare, Salt Lake City, UT; David G. Hicks, University of Rochester Medical Center, Rochester, NY; Mitch Dowsett, Royal Marsden Hospital, London, United Kingdom; Kimberly H. Allison, Stanford University Medical Center, Stanford; Patrick Fitzgibbons, St Jude Medical Center, Fullerton; Michael F. Press, University of Southern California, Los Angeles, CA; Donald C. Allred, Washington University School of Medicine, St Louis, MO; John M.S. Bartlett, Ontario Institute for Cancer Research; Wedad Hanna, Sunnybrook Health Sciences Center, Toronto, Ontario, Canada; Michael Bilous, University of Western Sydney and Healthscope Pathology, Sydney, New South Wales, Australia; Robert B. Jenkins, Mayo Clinic, Rochester, MN; Pamela B. Mangu, American Society of Clinical Oncology, Alexandria, VA; Soonmyung Paik, National Surgical Adjuvant Breast and Bowel Project, Pitsburgh, PA; Edith A. Perez, Mayo Clinic, Jacksonville, FL; Patricia A. Spears, North Carolina State University, Raleigh,
NC; Gail H. Vance, Indiana University Medical Center, Indianapolis, IN; Giuseppe Viale, University of Milan, European Institute of Oncology, Milan, Italy; and Daniel F. Hayes, University of Michigan Comprehensive Cancer Care Center, Ann Arbor, MI.

\section{References}

1. Wolff AC, Hammond ME, Schwartz JN, et al: American Society of Clinical Oncology/College of American Pathologists guideline recommendations for human epidermal growth factor receptor 2 testing in breast cancer. J Clin Oncol 25:118-145, 2007

2. Wolff AC, Hammond ME, Schwartz JN, et al: American Society of Clinical Oncology/College of American Pathologists guideline recommendations for human epidermal growth factor receptor 2 testing in breast cancer. Arch Pathol Lab Med 131:18-43, 2007

3. Hammond EH, Wolff AC, Hayes DF, et al: Reply to Sauter G. et al. J Clin Oncol 27:e153-e154, 2009; author reply e155-e157

4. Hammond ME, Hayes DF, Wolff AC: Clinical notice for American Society of Clinical Oncology-College of American Pathologists guideline recommendations on ER/PgR and HER2 testing in breast cancer. J Clin Oncol 29:e458, 2011

5. Wolff AC, Hammond ME, Hayes DF: Re: Predictability of adjuvant trastuzumab benefit in N9831 patients using the ASCO/CAP HER2-positivity criteria. J Natl Cancer Inst 104:957-958, 2012

6. Dowsett M, Procter M, McCaskill-Stevens W, et al: Disease-free survival according to degree of HER2 amplification for patients treated with adjuvant chemotherapy with or without 1 year of trastuzumab: The HERA Trial. J Clin Oncol 27:2962-2969, 2009

7. Perez EA, Reinholz MM, Hillman DW, et al: HER2 and chromosome 17 effect on patient outcome in the N9831 adjuvant trastuzumab trial. J Clin Oncol 28:4307-4315, 2010

8. Vance GH, Barry TS, Bloom KJ, et al: Genetic heterogeneity in HER2 testing in breast cancer: Panel summary and guidelines. Arch Pathol Lab Med 133:611-612, 2009

9. Gunn S, Yeh IT, Lytvak I, et al: Clinical array-based karyotyping of breast cancer with equivocal HER2 status resolves gene copy number and reveals chromosome 17 complexity. BMC Cancer 10:396, 2010

10. Yeh IT, Martin MA, Robetorye RS, et al: Clinical validation of an array $\mathrm{CGH}$ test for HER2 status in breast cancer reveals that polysomy 17 is a rare event. Mod Pathol 22:1169-1175, 2009

11. Bartlett JM, Campbell FM, Mallon EA: Determination of HER2 amplification by in situ hybridization: When should chromosome 17 also be determined? Am J Clin Pathol 130:920-926, 2008

12. Shah SS, Wang Y, Tull J, et al: Effect of high copy number of HER2 associated with polysomy 17 on HER2 protein expression in invasive breast carcinoma. Diagn Mol Pathol 18:30-33, 2009

13. Bartlett Al, Starcyznski J, Robson T, et al: Heterogeneous HER2 gene amplification: Impact on patient outcome and a clinically relevant definition. Am J Clin Pathol 136:266-274, 2011

14. Marchiò C, Lambros MB, Gugliotta P, et al: Does chromosome 17 centromere copy number predict polysomy in breast cancer? A fluorescence in situ hybridization and microarray-based CGH analysis. J Pathol 219:16-24, 2009

15. Troxell ML, Bangs CD, Lawce HJ, et al: Evaluation of Her-2/neu status in carcinomas with amplified chromosome 17 centromere locus. Am J Clin Pathol 126:709-716, 2006

16. Starczynski J, Atkey N, Connelly $\mathrm{Y}$, et al: HER2 gene amplification in breast cancer: A rogues' gallery of challenging diagnostic cases-UKNEQAS interpretation guidelines and research recommendations. Am J Clin Pathol 137: 595-605, 2012

17. Chang MC, Malowany JI, Mazurkiewicz J, et al: "Genetic heterogeneity" in HER2/neu testing by fluorescence in situ hybridization: A study of 2,522 cases. Mod Pathol 25:683-688, 2012

18. Moeder CB, Giltnane JM, Harigopal M, et al: Quantitative justification of the change from $10 \%$ to $30 \%$ for human epidermal growth factor receptor 2 scoring in the American Society of Clinical Oncology/ College of American Pathologists guidelines: Tumor heterogeneity in breast cancer and its implications for tissue microarray based assessment of outcome. J Clin Oncol 25:5418-5425, 2007

19. Gerlinger M, Rowan AJ, Horswell S, et al: Intratumor heterogeneity and branched evolution revealed by multiregion sequencing. N Engl J Med 366:883892, 2012

20. Ohlschlegel $C$, Zahel $K$, Kradolfer D, et al: HER2 genetic heterogeneity in breast carcinoma. J Clin Pathol 64:1112-1116, 2011

21. Mrhalova M, Kodet R: A modified approach for I-FISH evaluation of ERBB2 (HER-2) gene copy numbers in breast carcinomas: Comparison with HER2/CEP17 ratio system. J Cancer Res Clin Oncol 133:321-329, 2007

22. Perez EA, Press MF, Dueck AC, et al: Immunohistochemistry and fluorescence in situ hybridization assessment of HER2 in clinical trials of adjuvant therapy for breast cancer (NCCTG N9831, BCIRG 006, and BCIRG 005). Breast Cancer Res Treat 138:99-108, 2013

23. Hanna WM, Rüschoff J, Bilous $M$, et al: HER2 in situ hybridization in breast cancer: Clinical implications of polysomy 17 and genetic heterogeneity. Mod Pathol [epub ahead of print on June 28, 2013]

24. Perez EA, Suman VJ, Davidson NE, et al: Cardiac safety analysis of doxorubicin and cyclophosphamide followed by paclitaxel with or without trastuzumab in the North Central Cancer Treatment Group N9831 adjuvant breast cancer trial. J Clin Oncol 26:1231-1238, 2008 
25. Russell SD, Blackwell KL, Lawrence J, et al: Independent adjudication of symptomatic heart failure with the use of doxorubicin and cyclophosphamide followed by trastuzumab adjuvant therapy: A combined review of cardiac data from the National Surgical Adjuvant breast and Bowel Project B-31 and the North Central Cancer Treatment Group N9831 clinical trials. J Clin Oncol 28:34163421, 2010

26. Romond $\mathrm{EH}$, Jeong JH, Rastogi $\mathrm{P}$, et al: Seven-year follow-up assessment of cardiac function in NSABP B-31, a randomized trial comparing doxorubicin and cyclophosphamide followed by paclitaxel (ACP) with ACP plus trastuzumab as adjuvant therapy for patients with node-positive, human epidermal growth factor receptor 2-positive breast cancer. J Clin Oncol 30:3792-3799, 2012

27. Bowles EJ, Wellman R, Feigelson HS, et al: Risk of heart failure in breast cancer patients after anthracycline and trastuzumab treatment: A retrospective cohort study. J Natl Cancer Inst 104:1293-1305, 2012

28. Slamon DJ, Leyland-Jones B, Shak S, et al: Use of chemotherapy plus a monoclonal antibody against HER2 for metastatic breast cancer that overexpresses HER2. N Engl J Med 344:783-792, 2001

29. Smith I, Procter M, Gelber RD, et al: 2-year follow-up of trastuzumab after adjuvant chemotherapy in HER2-positive breast cancer: A randomised controlled trial. Lancet 369:29-36, 2007

30. Perez EA, Romond EH, Suman VJ, et al: Four-year follow-up of trastuzumab plus adjuvant chemotherapy for operable human epidermal growth factor receptor 2-positive breast cancer: Joint analysis of data from NCCTG N9831 and NSABP B-31. J Clin Oncol 29:3366-3373, 2011

31. Gianni L, Dafni U, Gelber RD, et al: Treatment with trastuzumab for 1 yea after adjuvant chemotherapy in patients with HER2-positive early breast cancer: A 4-year follow-up of a randomised controlled trial. Lancet Oncol 12:236-244, 2011

32. Geyer CE, Forster J, Lindquist D, et al: Lapatinib plus capecitabine for HER2-positive advanced breast cancer. N Engl J Med 355:2733-2743, 2006

33. Baselga J, Cortés J, Kim SB, et al: Pertuzumab plus trastuzumab plus docetaxel for metastatic breast cancer. N Engl J Med 366:109-119, 2012

34. Verma S, Miles D, Gianni L, et al: Trastuzumab emtansine for HER2 positive advanced breast cancer. N Engl J Med 367:1783-1791, 2012

35. Press MF, Finn RS, Cameron D, et al: HER-2 gene amplification, HER-2 and epidermal growth factor receptor mRNA and protein expression, and lapatinib efficacy in women with metastatic breast cancer. Clin Cancer Res 14 7861-7870, 2008

36. Gianni L, Llado A, Bianchi G, et al: Open-label, phase II, multicenter randomized study of the efficacy and safety of two dose levels of pertuzumab, human epidermal growth factor receptor 2 dimerization inhibitor, in patients with human epidermal growth factor receptor 2-negative metastatic breast cancer. Clin Oncol 28:1131-1137, 2010

37. Hurvitz SA, Dirix L, Kocsis J, et al: Phase II randomized study of trastuzumab emtansine versus trastuzumab plus docetaxel in patients with human epidermal growth factor receptor 2-positive metastatic breast cancer. J Clin Oncol 31:1157-1163, 2013

38. Paik S, Kim C, Wolmark N: HER2 status and benefit from adjuvant trastuzumab in breast cancer. N Engl J Med 358:1409-1411, 2008

39. Middleton LP, Price KM, Puig P, et al: Implementation of American Society of Clinical Oncology/College of American Pathologists HER2 guideline recommendations in a tertiary care facility increases HER2 immunohistochemistry and fluorescence in situ hybridization concordance and decreases the number of inconclusive cases. Arch Pathol Lab Med 133:775-780, 2009

40. Bartlett JM, Ibrahim M, Jasani B, et al: External quality assurance of HER2 FISH and ISH testing: Three years of the UK national external quality assurance scheme. Am J Clin Pathol 131:106-111, 2009

41. Brunelli M, Manfrin E, Martignoni G, et al: HER-2/neu assessment in breast cancer using the original FDA and new ASCO/CAP guideline recommendations: Impact on selecting patients for herceptin therapy. Am J Clin Pathol 129: 907-911, 2008

42. Reiner-Concin A, Regitnig P, Dinges HP, et al: Practice of HER-2 immunohistochemistry in breast carcinoma in Austria. Pathol Oncol Res 14 253-259, 2008

43. Khoury T, Sait S, Hwang $\mathrm{H}$, et al: Delay to formalin fixation effect on breast biomarkers. Mod Pathol 22:1457-1467, 2009

44. Tong LC, Nelson N, Tsourigiannis J, et al: The effect of prolonged fixation on the immunohistochemical evaluation of estrogen receptor, progesterone receptor, and HER2 expression in invasive breast cancer: A prospective study. Am J Surg Pathol 35:545-552, 2011

45. Hanley KZ, Birdsong GG, Cohen C, et al: Immunohistochemical detection of estrogen receptor, progesterone receptor, and human epiderma growth factor receptor 2 expression in breast carcinomas: Comparison on cell block, needle-core, and tissue block preparations. Cancer 117:279-288, 2009

46. Arber DA: Effect of prolonged formalin fixation on the immunohistochemical reactivity of breast markers. Appl Immunohistochem Mol Morphol 10 $183-186,2002$

47. Ibarra JA, Rogers LW: Fixation time does not affect expression of HER2/ neu: A pilot study. Am J Clin Pathol 134:594-596, 2010

48. McCullough AE, Dell'Orto P, Reinholz MM, et al: Concordance of HER2 central assessment by two international central laboratories: A ring study within the framework of the adjuvant HER2-positive ALTTO trial (BIG2-06/N063D/ EGF106708). Cancer Res 70, 2012 (suppl 2; abstr P3-10-36)

49. Perez EA, Dueck AC, McCullough AE, et al: Predictability of adjuvant trastuzumab benefit in N9831 patients using the ASCO/CAP HER2-positivity criteria. J Natl Cancer Inst 104:159-162, 2012
50. Iorfida $M$, Dellapasqua S, Bagnardi V, et al: HER2-negative (1+) breast cancer with unfavorable prognostic features: To FISH or not to FISH? Ann Oncol 23:1371-1372, 2012

51. Hameed O, Adams AL, Baker AC, et al: Using a higher cutoff for the percentage of HER2+ cells decreases interobserver variability in the interpretation of HER2 immunohistochemical analysis. Am J Clin Pathol 130:425-427, 2008

52. Atkinson R, Mollerup J, Laenkholm AV, et al: Effects of the change in cutoff values for human epidermal growth factor receptor 2 status by immunohistochemistry and fluorescence in situ hybridization: A study comparing conventional brightfield microscopy, image analysis-assisted microscopy, and interobserver variation. Arch Pathol Lab Med 135:1010-1016, 2011

53. Gilcrease MZ, Woodward WA, Nicolas MM, et al: Even low-level HER2 expression may be associated with worse outcome in node-positive breast cancer. Am J Surg Pathol 33:759-767, 2009

54. Niikura N, Liu J, Hayashi N, et al: Loss of human epidermal growth factor receptor 2 (HER2) expression in metastatic sites of HER2-overexpressing primary breast tumors. J Clin Oncol 30:593-599, 2012

55. Vincent-Salomon A, Pierga JY, Couturier J, et al: HER2 status of bone marrow micrometastasis and their corresponding primary tumours in a pilot study of 27 cases: A possible tool for anti-HER2 therapy management? Br J Cancer 96: 654-659, 2007

56. Santiago MP, Vázquez-Boquete A, Fernández B, et al: Whether to determine HER2 status for breast cancer in the primary tumour or in the metastasis. Histol Histopathol 24:675-682, 2009

57. Wilking U, Karlsson E, Skoog L, et al: HER2 status in a population-derived breast cancer cohort: Discordances during tumor progression. Breast Cancer Res Treat 125:553-561, 2011

58. Bates M, Sperinde J, Köstler WJ, et al: Identification of a subpopulation of metastatic breast cancer patients with very high HER2 expression levels and possible resistance to trastuzumab. Ann Oncol 22:2014-2020, 2011

59. Lower EE, Glass E, Blau R, et al: HER-2/neu expression in primary and metastatic breast cancer. Breast Cancer Res Treat 113:301-306, 2009

60. Guarneri V, Giovannelli S, Ficarra G, et al: Comparison of HER-2 and hormone receptor expression in primary breast cancers and asynchronous paired metastases: Impact on patient management. Oncologist 13:838-844, 2008

61. Tapia C, Savic S, Wagner U, et al: HER2 gene status in primary breast cancers and matched distant metastases. Breast Cancer Res 9:R31, 2007

62. Mittendorf EA, Wu Y, Scaltriti M, et al: Loss of HER2 amplification following trastuzumab-based neoadjuvant systemic therapy and survival outcomes. Clin Cancer Res 15:7381-7388, 2009

63. Bartlett JM, Ellis IO, Dowsett M, et al: Human epidermal growth factor receptor 2 status correlates with lymph node involvement in patients with estrogen receptor (ER) negative, but with grade in those with ER-positive earlystage breast cancer suitable for cytotoxic chemotherapy. J Clin Oncol 25:44234430, 2007

64. Amir E, Clemons M, Purdie CA, et al: Tissue confirmation of disease recurrence in breast cancer patients: Pooled analysis of multi-centre, multidisciplinary prospective studies. Cancer Treat Rev 38:708-714, 2012

65. Arnedos $M$, Nerurkar A, Osin P, et al: Discordance between core needle biopsy $(\mathrm{CNB})$ and excisional biopsy $(\mathrm{EB})$ for estrogen receptor (ER), progesterone receptor (PgR) and HER2 status in early breast cancer (EBC). Ann Oncol 20:19481952, 2009

66. Lebeau A, Turzynski A, Braun S, et al: Reliability of human epidermal growth factor receptor 2 immunohistochemistry in breast core needle biopsies. Clin Oncol 28:3264-3270, 2010

67. D'Alfonso T, Liu YF, Monni S, et al: Accurately assessing her-2/neu status in needle core biopsies of breast cancer patients in the era of neoadjuvant therapy: Emerging questions and considerations addressed. Am J Surg Pathol 34: 575-581, 2010

68. Apple SK, Lowe AC, Rao PN, et al: Comparison of fluorescent in situ hybridization HER-2/neu results on core needle biopsy and excisional biopsy in primary breast cancer. Mod Pathol 22:1151-1159, 2009

69. Chivukula M, Bhargava R, Brufsky A, et al: Clinical importance of HER2 immunohistologic heterogeneous expression in core-needle biopsies vs resection specimens for equivocal (immunohistochemical score 2+) cases. Mod Pathol 21: $363-368,2008$

70. Wood B, Junckerstorff R, Sterrett G, et al: A comparison of immunohistochemical staining for oestrogen receptor, progesterone receptor and HER-2 in breast core biopsies and subsequent excisions. Pathology 39:391-395, 2007

71. Zustin J, Boddin K, Tsourlakis MC, et al: HER-2/neu analysis in breast cancer bone metastases. J Clin Pathol 62:542-546, 2009

72. Komatsu K, Nakanishi Y, Seki T, et al: Application of liquid-based preparation to fine needle aspiration cytology in breast cancer. Acta Cytol 52: 591-596, 2008

73. Aitken SI, Thomas JS, Langdon SP, et al: Quantitative analysis of changes in ER, PR and HER2 expression in primary breast cancer and paired nodal metastases. Ann Oncol 21:1254-1261, 2010

74. Bilous M: Breast core needle biopsy: Issues and controversies. Mod Patho 23:S36-S45, 2010 (suppl 2)

75. Hammond ME, Hayes DF, Dowsett M, et al: American Society of Clinical Oncology/College of American Pathologists guideline recommendations for immunohistochemical testing of estrogen and progesterone receptors in breast cancer. Arch Pathol Lab Med 134:907-922, 2010

76. Hammond ME, Hayes DF, Dowsett M, et al: American Society of Clinica Oncology/College of American Pathologists guideline recommendations for 
immunohistochemical testing of estrogen and progesterone receptors in breast cancer. J Clin Oncol 28:2784-2795, 2010

77. Genentech: Highlights of prescribing information (Herceptin; trastuzumab) 2013. http://www.gene.com/download/pdf/herceptin_prescribing.pdf

78. Genentech: Highlights of prescribing information (Perjeta; pertuzumab) 2013. http://www.gene.com/download/pdf/perjeta_prescribing.pdf

79. Chibon F, de Mascarel I, Sierankowski G, et al: Prediction of HER2 gene status in Her2 2+ invasive breast cancer: A study of 108 cases comparing ASCO/ CAP and FDA recommendations. Mod Pathol 22:403-409, 2009

80. Mayr D, Heim S, Weyrauch K, et al: Chromogenic in situ hybridization for Her-2/neu-oncogene in breast cancer: Comparison of a new dual-colour chromogenic in situ hybridization with immunohistochemistry and fluorescence in situ hybridization. Histopathology 55:716-723, 2009

81. Tse $\mathrm{CH}$, Hwang $\mathrm{HC}$, Goldstein LC, et al: Determining true HER2 gene status in breast cancers with polysomy by using alternative chromosome 17 reference genes: Implications for anti-HER2 targeted therapy. J Clin Oncol 29: 4168-4174, 2011

82. Vanden Bempt I, Van Loo P, Drijkoningen M, et al: Polysomy 17 in breast cancer: Clinicopathologic significance and impact on HER-2 testing. J Clin Oncol 26:4869-4874, 2008

83. Sińczak-Kuta A, Tomaszewska R, Rudnicka-Sosin L, et al: Evaluation of HER2/neu gene amplification in patients with invasive breast carcinoma: Comparison of in situ hybridization methods. Pol J Pathol 58:41-50, 2007

84. Capizzi E, Gruppioni E, Grigioni AD, et al: Real time RT-PCR approach for the evaluation of ERBB2 overexpression in breast cancer archival samples: A comparative study with FISH, SISH, and immunohistochemistry. Diagn Mol Pathol 17:220-226, 2008

85. Powell WC, Roche PC, Tubbs RR: A new rabbit monoclonal antibody (4B5) for the immuno-histochemical (IHC) determination of the HER2 status in breast cancer: Comparison with CB11, fluorescence in situ hybridization (FISH), and interlaboratory reproducibility. Appl Immunohistochem Mol Morphol 16: 569,2008

86. Nunes CB, Rocha RM, Reis-Filho JS, et al: Comparative analysis of six different antibodies against Her2 including the novel rabbit monoclonal antibody (SP3) and chromogenic in situ hybridisation in breast carcinomas. J Clin Pathol 61:934-938, 2008

87. Gustavson MD, Bourke-Martin B, Reilly DM, et al: Development of an unsupervised pixel-based clustering algorithm for compartmentalization of immunohistochemical expression using Automated QUantitative Analysis. Appl Immunohistochem Mol Morphol 17:329-337, 2009

88. Egervari K, Szollosi Z, Nemes Z: Tissue microarray technology in breast cancer HER2 diagnostics. Pathol Res Pract 203:169-177, 2007

89. Minot DM, Kipp BR, Root RM, et al: Automated cellular imaging system III for assessing HER2 status in breast cancer specimens: Development of a standardized scoring method that correlates with FISH. Am J Clin Pathol 132: 133-138, 2009

90. Hall $\mathrm{BH}$, lanosi-Irimie $\mathrm{M}$, Javidian $\mathrm{P}$, et al: Computer-assisted assessment of the human epidermal growth factor receptor 2 immunohistochemical assay in imaged histologic sections using a membrane isolation algorithm and quantitative analysis of positive controls. BMC Med Imaging 8:11, 2008

91. Itoh H, Miyajima $\mathrm{Y}, \mathrm{Umemura} \mathrm{S}$, et al: Lower HER-2/chromosome enumeration probe 17 ratio in cytologic HER-2 fluorescence in situ hybridization for breast cancers: Three-dimensional analysis of intranuclear localization of centromere 17 and HER-2 signals. Cancer 114:134-140, 2008

92. Roepman $\mathrm{P}$, Horlings HM, Krijgsman O, et al: Microarray-based determination of estrogen receptor, progesterone receptor, and HER2 receptor status in breast cancer. Clin Cancer Res 15:7003-7011, 2009

93. Bartlett JM, Campbell FM, Ibrahim M, et al: A UK NEQAS ISH multicenter ring study using the Ventana HER2 dual-color ISH assay. Am J Clin Pathol 135: 157-162, 2011

94. Pedersen M, Rasmussen BB: The correlation between dual-color chromogenic in situ hybridization and fluorescence in situ hybridization in assessing HER2 gene amplification in breast cancer. Diagn Mol Pathol 18:96-102, 2009

95. Francis GD, Jones MA, Beadle GF, et al: Bright-field in situ hybridization for HER2 gene amplification in breast cancer using tissue microarrays: Correlation between chromogenic $(\mathrm{CISH})$ and automated silver-enhanced ( $\mathrm{SISH}$ ) methods with patient outcome. Diagn Mol Pathol 18:88-95, 2009

96. Gong Y, Sweet W, Duh YJ, et al: Performance of chromogenic in situ hybridization on testing HER2 Status in breast carcinomas with chromosome 17 polysomy and equivocal (2+) herceptest results: A study of two institutions using the conventional and new ASCO/CAP scoring criteria. Am J Clin Pathol 132:228236, 2009

97. Vocaturo A, Novelli F, Benevolo $M$, et al: Chromogenic in situ hybridization to detect HER-2/neu gene amplification in histological and ThinPrep-processed breast cancer fine-needle aspirates: A sensitive and practical method in the trastuzumab era. Oncologist 11:878-886, 2006

98. Hanna WM, Kwok K: Chromogenic in-situ hybridization: A viable alternative to fluorescence in-situ hybridization in the HER2 testing algorithm. Mod Pathol 19:481-487, 2006

99. Rocha RM, Nunes CB, Sanches FS, et al: Rabbit antibodies for hormone receptors and HER2 evaluation in breast cancer. Rev Assoc Med Bras 55:163168,2009

100. Cayre A, Mishellany F, Lagarde N, et al: Comparison of different commercial kits for HER2 testing in breast cancer: Looking for the accurate cutoff for amplification. Breast Cancer Res 9:R64, 2007
101. García-Caballero T, Grabau D, Green AR, et al: Determination of HER2 amplification in primary breast cancer using dual-colour chromogenic in situ hybridization is comparable to fluorescence in situ hybridization: A European multicentre study involving 168 specimens. Histopathology 56:472-480, 2010

102. Di Palma S, Collins N, Faulkes C, et al: Chromogenic in situ hybridisation $(\mathrm{CISH})$ should be an accepted method in the routine diagnostic evaluation of HER2 status in breast cancer. J Clin Pathol 60:1067-1068, 2007

103. Sáez A, Andreu FJ, Seguí MA, et al: HER-2 gene amplification by chromogenic in situ hybridisation $(\mathrm{CISH})$ compared with fluorescence in situ hybridisation (FISH) in breast cancer-A study of two hundred cases. Breast 15: 519-527, 2006

104. Baehner FL, Achacoso N, Maddala T, et al: Human epidermal growth factor receptor 2 assessment in a case-control study: Comparison of fluorescence in situ hybridization and quantitative reverse transcription polymerase chain reaction performed by central laboratories. J Clin Oncol 28:4300-4306, 2010

105. Shousha S, Peston D, Amo-Takyi B, et al: Evaluation of automated silverenhanced in situ hybridization (SISH) for detection of HER2 gene amplification in breast carcinoma excision and core biopsy specimens. Histopathology 54:248253, 2009

106. Faratian D, Graham A, Rae F, et al: Rapid screening of tissue microarrays for Her-2 fluorescence in situ hybridization testing is an accurate, efficient and economic method of providing an entirely in situ hybridization-based Her-2 testing service. Histopathology 54:428-432, 2009

107. Ni R, Mulligan AM, Have C, et al: PGDS, a novel technique combining chromogenic in situ hybridization and immunohistochemistry for the assessment of ErbB2 (HER2/neu) status in breast cancer. Appl Immunohistochem Mol Morphol 15:316-324, 2007

108. Uzan C, Andre F, Scott V, et al: Fine-needle aspiration for nucleic acidased molecular analyses in breast cancer. Cancer 117:32-39, 2009

109. Cuadros M, Talavera P, López FJ, et al: Real-time RT-PCR analysis for evaluating the Her2/neu status in breast cancer. Pathobiology 77:38-45, 2010

110. Susini T, Bussani C, Marini G, et al: Preoperative assessment of HER-2/ neu status in breast carcinoma: The role of quantitative real-time PCR on corebiopsy specimens. Gynecol Oncol 116:234-239, 2010

111. Huang W, Reinholz M, Weidler J, et al: Comparison of central HER2 testing with quantitative total HER2 expression and HER2 homodimer measurements using a novel proximity-based assay. Am J Clin Pathol 134:303-311, 2010

112. Ashok M, Griffin P, Halpern M: Impact of clinical and non-clinical factors on the choice of HER2 test for breast cancer. Cancer Invest 28:735-742, 2010

113. Joensuu $H$, Sperinde J, Leinonen $M$, et al: Very high quantitative tumor HER2 content and outcome in early breast cancer. Ann Oncol 22:2007-2013, 2011

114. Monego G, Arena V, Maggiano N, et al: Borderline HER-2 breast cancer cases: Histochemical versus real-time PCR analysis and impact of different cut-off values. Scand J Clin Lab Invest 67:402-412, 2007

115. Dobson L, Conway C, Hanley A, et al: Image analysis as an adjunct to manual HER-2 immunohistochemical review: A diagnostic tool to standardize interpretation. Histopathology 57:27-38, 2010

116. Masmoudi $\mathrm{H}$, Hewitt SM, Petrick $\mathrm{N}$, et al: Automated quantitative assessment of HER-2/neu immunohistochemical expression in breast cancer. IEEE Trans Med Imaging 28:916-925, 2009

117. Giltnane JM, Molinaro A, Cheng $\mathrm{H}$, et al: Comparison of quantitative immunofluorescence with conventional methods for HER2/neu testing with respect to response to trastuzumab therapy in metastatic breast cancer. Arch Pathol Lab Med 132:1635-1647, 2008

118. Tubbs RR, Pettay JD, Swain E, et al: Automation of manual components and image quantification of direct dual label fluorescence in situ hybridization (FISH) for HER2 gene amplification: A feasibility study. Appl Immunohistochem Mol Morphol 14:436-440, 2006

119. Skaland I, Ovestad I, Janssen EA, et al: Digital image analysis improves the quality of subjective HER-2 expression scoring in breast cancer. Appl Immunohistochem Mol Morphol 16:185-190, 2008

120. Skaland I, Ovestad I, Janssen EA, et al: Comparing subjective and digital image analysis HER2/neu expression scores with conventional and modified FISH scores in breast cancer. J Clin Pathol 61:68-71, 2008

121. Słodkowska J, Filas V, Buszkiewicz E, et al: Study on breast carcinoma Her2/neu and hormonal receptors status assessed by automated images analysis systems: ACIS III (Dako) and ScanScope (Aperio). Folia Histochem Cytobiol 48: 19-25, 2010

122. Flanagan MB, Dabbs DJ, Brufsky AM, et al: Histopathologic variables predict Oncotype DX recurrence score. Mod Pathol 21:1255-1261, 2008

123. Cuzick J, Dowsett M, Pineda S, et al: Prognostic value of a combined estrogen receptor, progesterone receptor, $\mathrm{Ki}-67$, and human epidermal growth factor receptor 2 immunohistochemical score and comparison with the Genomic Health recurrence score in early breast cancer. J Clin Oncol 29:4273-4278, 2011

124. Dabbs DJ, Klein ME, Mohsin SK, et al: High false-negative rate of HER2 quantitative reverse transcription polymerase chain reaction of the Oncotype DX test: An independent quality assurance study. J Clin Oncol 29:4279-4285, 2011

125. Nassar A, Cohen C, Siddiqui M: Estimation of hormone receptor status and HER2 in cytologic cell blocks from breast cancer using the novel rabbit monoclonal antibodies (SP1, SP2, and SP3). Diagn Cytopathol 37:865-870, 2009

126. Francz M, Egervari K, Kardos L, et al: Comparison of Pathvysion and Poseidon HER2 FISH assays in measuring HER2 amplification in breast cancer: A validation study. J Clin Pathol 63:341-346, 2010 
127. Bergqvist J, Ohd JF, Smeds J, et al: Quantitative real-time PCR analysis and microarray-based RNA expression of HER2 in relation to outcome. Ann Oncol 18:845-850, 2007

128. Barberis $M$, Pellegrini $C$, Cannone $M$, et al: Quantitative PCR and HER2 testing in breast cancer: A technical and cost-effectiveness analysis. Am J Clin Pathol 129:563-570, 2008

129. Potemski P, Płuciennik E, Bednarek AK, et al: A comparative assessment of HER2 status in operable breast cancer by real-time RT-PCR and by immunohistochemistry. Med Sci Monit 12:MT57-MT61, 2006

130. Papouchado BG, Myles J, Lloyd RV, et al: Silver in situ hybridization (SISH) for determination of HER2 gene status in breast carcinoma: Comparison with FISH and assessment of interobserver reproducibility. Am J Surg Pathol 34 767-776, 2010

131. Ricardo SA, Milanezi F, Carvalho ST, et al: HER2 evaluation using the novel rabbit monoclonal antibody SP3 and CISH in tissue microarrays of invasive breast carcinomas. J Clin Pathol 60:1001-1005, 2007

132. Graham AD, Faratian D, Rae F, et al: Tissue microarray technology in the routine assessment of HER-2 status in invasive breast cancer: A prospective study of the use of immunohistochemistry and fluorescence in situ hybridization. Histopathology 52:847-855, 2008

133. Mayr D, Heim S, Werhan C, et al: Comprehensive immunohistochemical analysis of Her-2/neu oncoprotein overexpression in breast cancer: HercepTest (Dako) for manual testing and Her-2/neuTest 4B5 (Ventana) for Ventana BenchMark automatic staining system with correlation to results of fluorescence in situ hybridization (FISH). Virchows Arch 454:241-248, 2009

134. Wludarski SC, Bacchi CE: High concordance of SP3 rabbit monoclonal antibody with FISH to evaluate HER2 in breast carcinoma. Appl Immunohistochem Mol Morphol 16:466-470, 2008

135. Ignatiadis $M$, Xenidis N, Perraki $M$, et al: Different prognostic value of cytokeratin-19 mRNA positive circulating tumor cells according to estrogen receptor and HER2 status in early-stage breast cancer. J Clin Oncol 25:51945202, 2007

136. Dowsett M, Hanna WM, Kockx M, et al: Standardization of HER2 testing: Results of an international proficiency-testing ring study. Mod Pathol 20:584-591, 2007

137. Bartlett JM, Campbell FM, Ibrahim M, et al: A UK NEQAS ICC and ISH multicentre study using the Kreatech Poseidon HER2 FISH probe: Intersite variation can be rigorously controlled using FISH. Histopathology 56:297-304, 2010

138. Simon RM, Paik S, Hayes DF: Use of archived specimens in evaluation of prognostic and predictive biomarkers. I Natl Cancer Inst 101:1446-1452, 2009

139. Teutsch SM, Bradley LA, Palomaki GE, et al: The Evaluation of Genomic Applications in Practice and Prevention (EGAPP) initiative: Methods of the EGAPP Working Group. Genet Med 11:3-14, 2009

140. Reddy JC, Reimann JD, Anderson SM, et al: Concordance between central and local laboratory HER2 testing from a community-based clinical study. Clin Breast Cancer 7:153-157, 2006
141. Sui W, Ou M, Chen I, et al: Comparison of immunohistochemistry (IHC) and fluorescence in situ hybridization (FISH) assessment for Her-2 status in breast cancer. World J Surg Oncol 7:83, 2009

142. van de Vijver M, Bilous M, Hanna W, et al: Chromogenic in situ hybridisation for the assessment of HER2 status in breast cancer: An international validation ring study. Breast Cancer Res 9:R68, 2007

143. Carbone A, Botti G, Gloghini A, et al: Delineation of HER2 gene status in breast carcinoma by silver in situ hybridization is reproducible among laboratories and pathologists. J Mol Diagn 10:527-536, 2008

144. Perez EA, Suman VJ, Davidson NE, et al: HER2 testing by local, central, and reference laboratories in specimens from the North Central Cancer Treatment Group N9831 intergroup adjuvant trial. J Clin Oncol 24:3032-3038, 2006

145. Vani K, Sompuram SR, Fitzgibbons P, et al: National HER2 proficiency test results using standardized quantitative controls: Characterization of laboratory failures. Arch Pathol Lab Med 132:211-216, 2008

146. Nofech-Mozes SJT, Hanna W, Khalifa M: Synoptic reporting on breast cancer biomarkers: A novel quality improvement module. Canadian J Pathol Winter 2011:11-15, 2011

147. American College of Physicians: Racial and Ethnic Disparities in Health Care 2010: Policy Paper. http://www.acponline.org/advocacy/current_policy_ papers/assets/racial_disparities.pdf

148. Howlader N, Noone AM, Krapcho M, et al (eds): SEER Cancer Statistics Review, 1975-2009 (vintage 2009 populations). http://seer.cancer.gov/csr/1975 2009_pops09/

149. Mead H, Cartwright-Smith L, Jones K, et al: Racial and ethnic disparities in U.S. health care: A chartbook. http://www.commonwealthfund.org/usr_doc/ Mead racialethnicdisparities_chartbook_1111.pdf

150. Smedley BD, Stith AY, Neson AR: Unequal Treatment: Confronting Racial and Ethnic Disparities in Health Care. Washington, DC, National Academies Press, 2003

151. Lund MJ, Butler EN, Hair BY, et al: Age/race differences in HER2 testing and in incidence rates for breast cancer triple subtypes: A population-based study and first report. Cancer 116:2549-2559, 2010

152. Sparano JA, Wang M, Zhao F, et al: Race and hormone receptor-positive breast cancer outcomes in a randomized chemotherapy trial. J Natl Cancer Inst 104:406-414, 2012

153. Ferrusi IL, Earle CC, Trudeau M, et al: Closing the personalized medicine information gap: HER2 test documentation practice. Am J Manag Care 19:838844,2013

154. Goddard KA, Weinmann $S$, Richert-Boe $K$, et al: HER2 evaluation and its impact on breast cancer treatment decisions. Public Health Genomics 15:1-10, 2012

155. Stark A, Kucera G, Lu M, et al: Influence of health insurance status on inclusion of HER-2/neu testing in the diagnostic workup of breast cancer patients. Int J Qual Health Care 16:517-521, 2004 